Aus der Klinik für Neurochirurgie

(Prof. Dr. med. V. Rohde)

der Medizinischen Fakultät der Universität Göttingen

\title{
HDAC inhibitor valproic acid increases CRABP2 expression and in combination with retinoic acid synergistically inhibits proliferation in glioblastoma cells
}

\author{
INAUGURAL-DISSERTATION \\ zur Erlangung des Doktorgrades \\ der Medizinischen Fakultät der \\ Georg-August-Universität zu Göttingen
}

vorgelegt von

Lei Yao

aus

Nanjing, Jiangsu, China

Göttingen 2016 
Dekan:

Referent/in

Ko-Referent/in:

Drittreferent/in:

Tag der mündlichen Prüfung:
Prof. Dr. rer. nat. H.K. Kroemer

Prof. Dr. V. Rohde

Prof. Dr. M. Dobbelstein

PD Dr. P. Thelen

14.12.2016 


\section{TABLE OF CONTENTS}

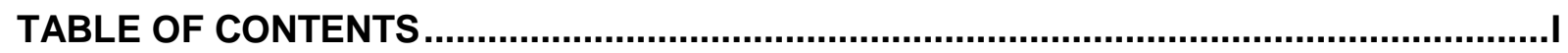

LIST OF FIGURES..................................................................................................

LIST OF TABLES ............................................................................................. IV

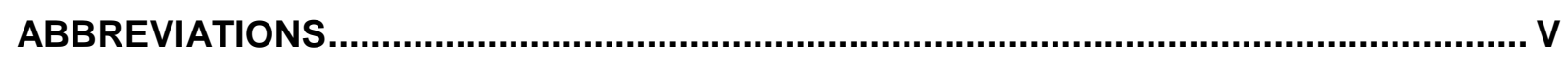

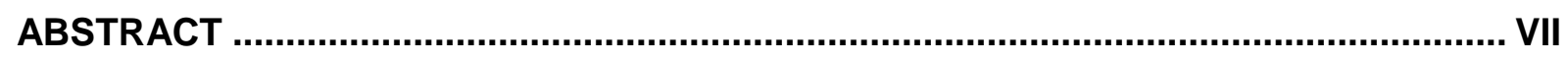

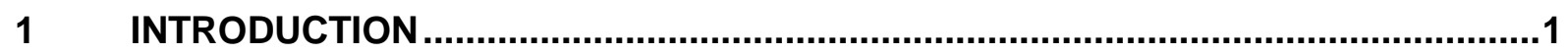

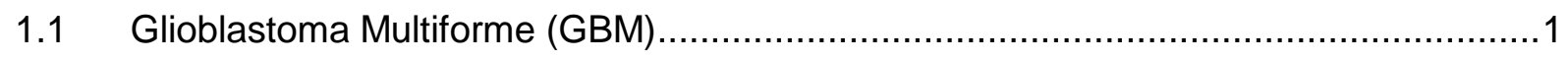

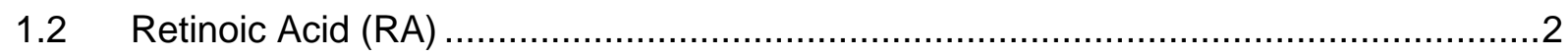

1.3 Cellular Retinoic Acid-Binding Protein 2 (CRABP2) in the RA pathway......................2

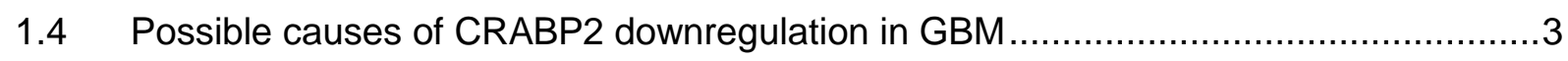

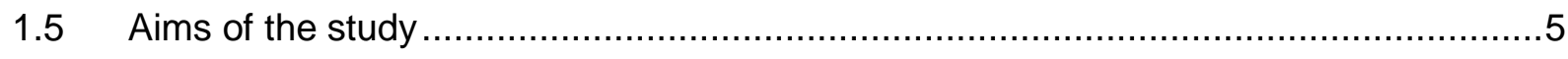

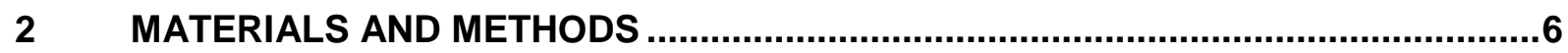

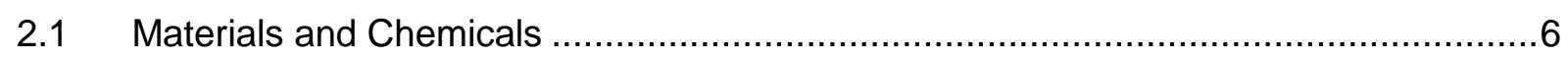

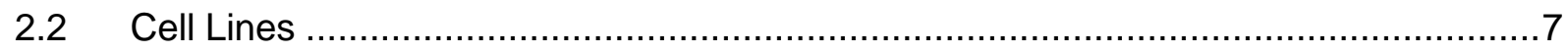

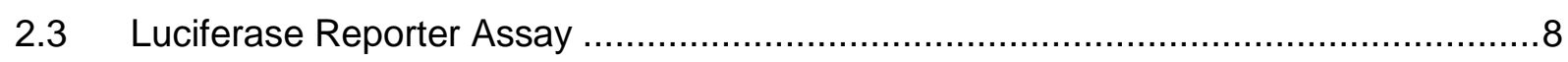

2.4 Construction of pcDNA4-CRABP2 plasmid and its transfection in U87MG .................

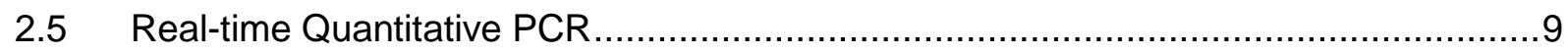

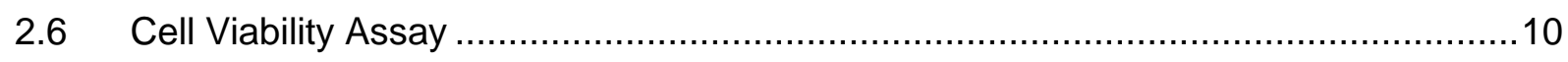

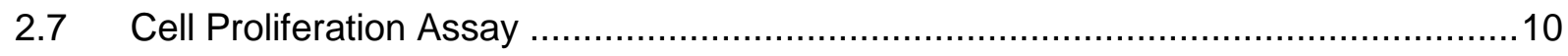

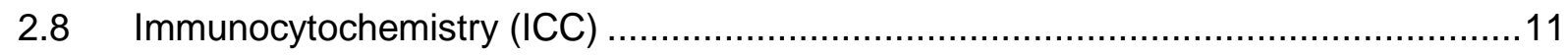

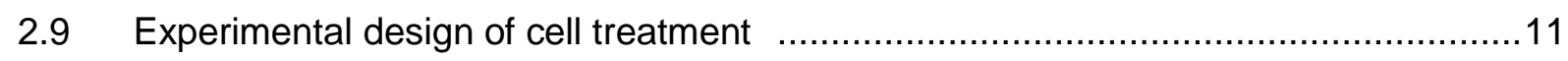

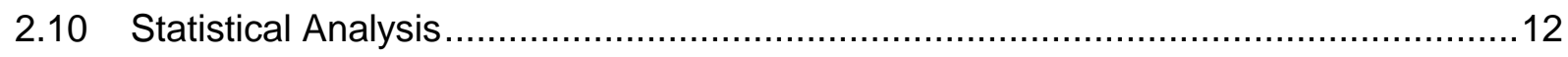

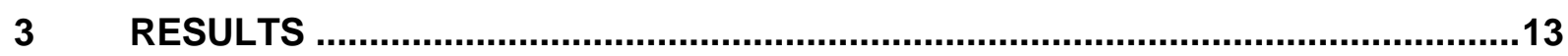


3.1 3' UTR of CRABP2 mRNA is not the target of hsa-mir-34a and hsa-mir-1262 in glioblastoma cells

3.2 Downregulation of CRABP2 protein in glioblastomas is not due to the mutation in

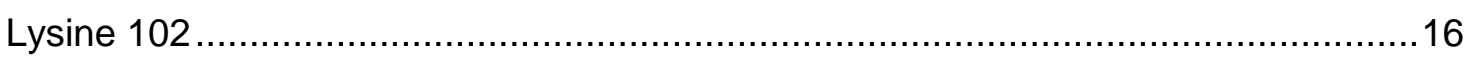

3.3 Effect of combined VPA and RA treatment on CRABP2 expression in GBM cells .....17

3.4 VPA treatment alone and in combination with RA inhibit proliferation and cell viability of GBM cells.....

3.5 VPA treatment as well as DNA methylation Inhibitor 5-aza decrease DNMT1 levels in GBM cells .25

3.6 Overexpression of CRABP2 as well as VPA treatment increase apoptosis in vitro ....28

4 DISCUSSION. 33

4.1 Decrease of CRABP2 in GBM is not modulated by hsa-mir-34a and hsa-mir-1262 and mutation in $\mathrm{K} 102$ .33

4.2 CRABP2 expression increases after VPA treatment in GBM cells ...........................34

4.3 Nuclear re-localization of CRABP2 after VPA+RA in GBM cells .............................34

4.4 VPA+RA treatment increased apoptosis and decreased proliferation in GBM cells ...35

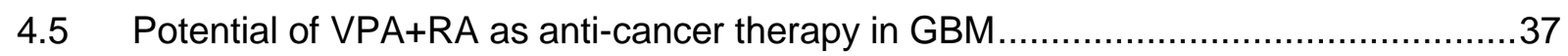

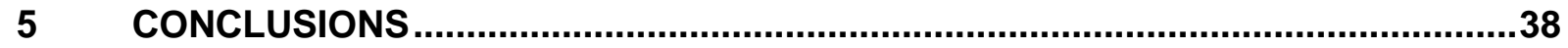

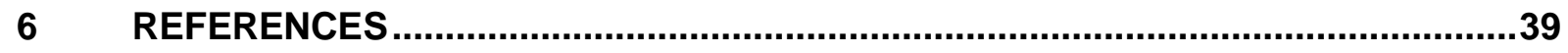




\section{LIST OF FIGURES}

Figure 1: The hypothetic target positions of hsa-mir-34a or hsa-mir-1262 on CRABP2 mRNA 3'UTR according to microRNA database "miRwalk" and "miRBase".

Figure 2: Heat map presenting the expression profiles of hsa-mir-34a and hsa-mir-1262 respectively in 17 low grade gliomas and 17 GBM tissues

Figure 3: Real-time PCR analysis of data from TCGA showed that hsa-mir-34a and hsa-mir1262 were increased significantly in 17 low grade gliomas.

Figure 4: The construction of comercial pMIR-REPORT firefly luciferase vector, pGL4.73 renilla luciferase vector and constructed pMIR-REPORT-CRABP2-3'UTR firefly luciferase vector. .16

Figure 5: Schematic presentation of the experimental design.

Figure 6: Real-time PCR analysis showed that CRABP2 expression was increased significantly after combined VPA and RA treatment in GBM cells...

Figure 7: Real-time PCR analysis showed that the ratios of FABP5/CRABP2 were consequently decreased in $\mathrm{V}+\mathrm{R}$ group in GBM cells 19

Figure 8: VPA in combination with RA upregulate CRABP2 expression in GBM cells.

Figure 9: VPA treatment alone and in combination with RA inhibits proliferation and cell viability of GBM cells

Figure 10: The proportion of $\mathrm{Ki}-67$ positive cells in $\mathrm{V}+\mathrm{R}$ groups were considerably lower compared with NC or VPA single treatment group in GBM cells. .23

Figure 11: The cell viability in GBM cells was inhibited after 72 hours treatment with VPA alone and $\mathrm{V}+\mathrm{R}$ combination groups

Figure 12: The reduction of VPA concentration up to $2 \mathrm{mM}$ in combination with RA was still able to cause significant reduction in cell viability in GBM cells 25

Figure 13: The real-time PCR showed that DNA methylation inhibitor 5-aza significantly increased the expression of CRABP2 mRNA in U87MG

Figure 14: U87MG cell viability decreased notably in MTT assay by treatment with 5-aza and 5-aza combined with RA. .27

Figure 15: VPA treatment decreases DNMT1 levels in GBM cells 27 
Figure 16: The commercially available pcDNA4/myc-HisB plasmid, and constructed pcDNA4CRABP2 plasmid CRABP2 coding sequence .28

Figure 17: Overexpression of CRABP2 as well as VPA treatment increase apoptosis in vitro 29

Figure 18: CRABP2 expression level in GBM cells after transfection of pcDNA4-CRABP2 plasmid.

Figure 19: Caspase 7 mRNA level in GBM cells with over-expressing CRABP2. 30

Figure 20: In correlation with GBM cells over-expressing CRABP2, VPA-treated groups showed increased Caspase 7 mRNA expression 31

Figure 21: mRNA expression of anti-apoptotic marker Bcl-2 in GBM cells. 32

Figure 22: Hypothetical schematic representation of potential action of VPA+RA on CRABP2 expression in GBM cells .36

\section{LIST OF TABLES}

Tabel 1: Materials and chemicals and their sources used in the present study .6

Tabel 2: Cell transfection used in Luciferase Reporter Assay ........................................... 8

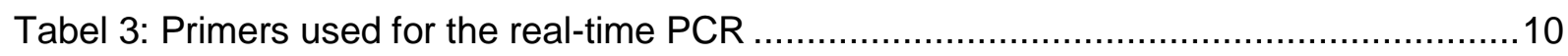




\section{ABBREVIATIONS}

5-aza 5-aza-2'-deoxycytidine

ATRA all-trans retinoic acid

Bax Bcl-2 associated $X$ protein

Bcl-2 B cell lymphoma 2

CNS central nervous system

CRABP2 cellular retinoic acid-binding protein 2

DAPI 4',6-diamidino-2-phenylindole

DMSO dimethylsulfoxide

DNA deoxyribonucleic acid

DNMT1 DNA methyltransferase 1

EDTA ethylene diamine tetraacetic acid

FABP5 fatty acid-binding protein 5

FBS fetal bovine serum

GBM glioblastoma multiforme

GSCs glioma stem cells

HDACi histone deacetylation inhibitor

HEK293 human embryonic kidney 293

HMBS hydroxymethylbilane synthase

ICC immunocytochemistry

K102 Lysine 102

IncRNAs long non-coding RNAs

LTS long term survivors

MEM minimum essential medium

mRNA messenger RNA

MTT 3-(4,5-dimethylthiazol)-2,5-diphenyltetrazolium bromide

NC negative control

NCOR2 nuclear receptor co-repressor 2 
NEAA non-essential amino acid

PBS phosphate-buffered saline

PI propidium iodide

PPAR peroxisomal proliferator activated receptor

RA retinoic acid

RAR retinoic acid receptors

RARE retinoic acid responsive elements

$\mathrm{RDH} \quad$ retinaldehyde

RNA ribonucleic acid

$\mathrm{RXR} \quad$ retinoid $X$ receptors

S.E.M standard error of the mean

STS short term survivors

TCGA The Cancer Genome Atlas

$\mathrm{TMZ}$ temozolomide

UTR 3'- untranslated region

VPA valproic acid

WHO World Health Organization 


\section{ABSTRACT}

Background: Although integrated treatments were implemented, glioblastoma multiforme (GBM) remains one of the most lethal primary brain tumors. The cellular retinoic acid-binding protein 2 (CRABP2) plays a crucial role, as one of the key cytoplasmic transport-proteins in retinoic acid (RA) pathway in various cancers, hence in GBM. Downregulation of CRABP2 protein and its lower ratio to fatty acidbinding protein 5 (FABP5) were showed to play important role in impaired RA pathway and in survival time of GBM patients. The specific mechanism of CRABP2 regulation in GBM is still not clear. Methods: Luciferase Reporter Assay was used to test hsa-mir-34a and hsa-mir-1262 mediated effects on 3'- untranslated region (3'UTR) of CRABP2 mRNA. In order to detect possible mutation in SUMOylation site, coding sequence of CRABP2 from different GBM tissues and cell lines was amplified and sequenced. Valproic acid (VPA) as histone deacetylation inhibitor, 5-aza-2'deoxycytidine (5-aza) as DNA methylation Inhibitor and RA were used to treat U87MG and patient-derived 36st GBM cell lines. Real-time PCR was used for mRNA quantification of CRABP2, FABP5, methyltransferase 1 (DNMT1), Caspase 7 and Bcl-2 DNA in cells treated with VPA, VPA+RA, 5-aza as well as in cells transfected with pcDNA4-CRABP2 plasmid. MTT assays were performed to detect GBM cells viability after VPA single and 5-aza single and in combination with RA treatment. Immunocytochemistry (ICC) was performed to detect expression of CRABP2 using anti-CRABP2, and proliferation level using anti-Ki-67 antibody. Results: Downregulation of CRABP2 in GBM is not due to its modulation by hsa-mir-34a and hsa-mir-1262 or a mutation in Lysine 102. VPA treatment alone and in combination with RA increased CRABP2 expression and inhibited proliferation and cell viability in GBM cells. Moreover, VPA treatment as well as 5-aza decreased DNMT 1 level in vitro. Besides that, both over-expression of CRABP2 as well as VPA treatment, increased apoptosis in glioblastoma cells. Conclusions: VPA increases expression of CRABP2 in analyzed GBM cell lines. Additional increase of CRABP2 expression was achieved by combined VPA and RA treatment. VPA+RA drug combination synergistically inhibited the proliferation of glioblastoma cells. This data suggests that VPA in combination with RA can be a promising anti-cancer therapy for GBM. 


\section{INTRODUCTION}

\subsection{Glioblastoma Multiforme (GBM)}

Within the central nervous system (CNS), human gliomas are recognized as the most common brain malignant neoplasia, which are classified as Grades I to IV according to the World Health Organization (WHO). Among that, GBM (WHO Grade IV glioblastoma) accounts for more than half of all gliomas and is the most lethal primary brain tumor in adults (Louis et al. 2007, Adamson et al. 2009).

Glioblastoma "multiforme" displays that the tumor not only has high heterogeneity in histopathology but also shows inhomogeneity in both intertumoral and intratumoral aspects. Although in GBM integrated treatments, including surgery, specific regional radiotherapy and temozolomide (TMZ) chemotherapy are performed, median survival is still 14.8 months and less than $5 \%$ of patients survive longer than 5 years after the diagnosis (Ohgaki and Kleihues 2005, Wen and Kesari 2008). However, Barbus et al. found that among GBM patients there were $3-5 \%$ that can survive three years or longer (long term survivors, LTS, overall survival $\geq 36$ months) (Barbus et al. 2011).

Consequently, over the past decades, thousands of studies worldwide aim to search for more specific anti-GBM therapy so called personalized therapy (Shirai and Chakravarti 2011). Distinct strategies were applied and involved in study of different oncogenic pathways as for example angiogenesis (Wang et al. 2016), tumor immunology (Garg et al. 2016), epigenetic events (Nagarajan and Costello 2009) and glioma stem cells (GSCs) (Codrici et al. 2016). Chemoresistance and lack of accurate and reproducible biomarkers to select patients for specific therapies remain all the time the major therapeutic problems in GBM patients. The regulation of proand anti-apoptotic pathways is a key factor in the onset and maintenance of chemoresistance, and it is crucial to develop some new treatment strategies for GBM patients. 


\subsection{Retinoic Acid (RA)}

Retinoids can induce differentiation and/or apoptosis from cancer cellular perspective and display anti-proliferative and anti-oxidative activity. For this reason retinoids possess huge potential as chemotherapeutics (Altucci and Gronemeyer 2001). In a series of enzymatic steps, vitamin A (retinol) is metabolized through the oxidizing action of retinaldehyde $(\mathrm{RDH})$ to retinal, and by retinaldehyde dehydrogenase (RALDH) to RA. RA has three different isomers: all-trans, 9-cis, and 13-cis RA. Alltrans RA (ATRA, RA) activates retinoic acid receptors (RAR $\alpha / \beta / \gamma)$, while 9-cis-RA activates RARs as well as retinoid $X$ receptors (RXR $\alpha / \beta / Y$ ) (Chambon 1996; Mangelsdorf 1994). RARs heterodimerize mostly with RXRs, which function as a transcription factor. RA, as an anti-carcinogenic agent, is currently used in the treatment of promyelocytic leukemia (Degos and Wang 2001, Chomienne et al. 1990), and is being tested as a therapy for several types of human cancers (Buntzel and Kuttner 1998, Niles 2002, Arrieta et al. 2011, Bryan et al. 2011). Even though some encouraging results have been obtained from a phase 2 pilot study of RA given to patients with progressive or recurrent malignant glioma (Yung et al. 1996), efficacy of retinoids in glioma patients in clinical trials has been limited (Kaba et al. 1997, Phuphanich et al. 1997). It has been demonstrated that RA resistance may stem from the deregulated retinoid signaling (Campos et al. 2015, Jing et al. 1997).

\subsection{Cellular Retinoic Acid-Binding Protein 2 (CRABP2) in the RA pathway}

CRABP2, as one of the key cytoplasmic transport-proteins, plays a crucial role in the RA pathway (Liu et al. 2016). As one of the vitamin A metabolic molecules, RA once bound to CRABP2, is transported from cytoplasm into the nucleus via the activation of a nuclear localization signal (Corlazzoli et al. 2009). CRABP2 has higher binding affinity towards intracellular RA and once RA binds to CRABP2, it is directly delivered to the RAR $\alpha$ and RXR $\alpha / \beta / Y$ (Campos et al. 2011). This complex then binds to specific responsive elements in the promoters of target gene (Retinoic Acid Responsive Elements, RARE), and subsequently induces the gene expression of its downstream target (Campos et al. 2011). RA-activated RARs are involved in the transcriptional regulation of genes involved in multiple biological processes, such as 
cell differentiation (Rochette-Egly and Chambon 2001), proliferation (Vreeland et al. 2014a), cell cycle arrest (Donato and Noy 2005, Donato et al. 2007) and apoptosis (Donato and Noy 2005).

Alternatively, FABP5 is an intracellular lipid-binding protein which competes with CRABP2 for the RA, but with a less binding affinity. FABP5 shuffles RA to another nuclear receptor Peroxisomal Proliferator Activated Receptor $\beta / \delta$ (PPAR $/ \delta)$, which activates the genes involved more in proliferation (Schug et al. 2007). Liu et al. (2011) showed that in the case of higher cytoplasmic FABP5 to CRABP2 ratio in breast cancer, RA was preferentially bound to FABP5, thus cell survival increases instead of building the complex with CRABP2 which would contribute to the decrease of tumor cell survival (Liu et al. 2011). The analysis of Barbus et al. (2011) of GBM patients displayed low FABP5 to CRABP2 ratio in LTS, whereas a high FABP5 to CRABP2 ratio was detected in short term survivors (STS, overall survival $\leq 6$ months) (Barbus et al. 2011).

Downregulation of CRABP2 in medulloblastoma is due to the aberrant methylation in the promoter region (Fu et al. 2012). Campos et al. (2012) revealed that CRABP2 expression is WHO grade-dependent (Campos et al. 2012). They also showed that downregulation of both total and nuclear CRABP2 plays a critical role in poor patient survival. Recently Yang et al. (2016) also stated that CRABP2 is downregulated in human esophageal squamous cell carcinoma and is considered as a tumor suppressor (Yang et al. 2016).

\subsection{Possible causes of CRABP2 downregulation in GBM}

Nagarajan and Costello (2009) classified epigenetic regulation in GBM as: noncoding RNAs, covalent modifications of DNA (such as DNA methylation) and posttranslational modifications of $\mathrm{N}$-terminal tails of histones (such as histone modifications) (Nagarajan and Costello 2009). Here the different types of epigenetic dysregulation are considered as potential reasons which could lead to downregulation of CRABP2 and deregulated RA pathway in GBM. 
MiRNAs as non-coding RNAs are a class of 21-25 nucleotide-long small RNAs (He and Hannon 2004). Chen et al. (2014) showed that RA induced expression of miRNA-302b which inhibits E2F3, a transcription factor leading to cell apoptosis in glioma (Chen et al. 2014). Furthermore, in neuroblastoma cells, Foley et al. (2011) also revealed that RA treatment induced expression of mir-10a/b which targets the nuclear receptor co-repressor 2 (NCOR2) (Foley et al. 2011). Downregulation of NCOR2 leads to the indirect suppression of MYCN, a potent onco-protein in neuroblastoma. This research demonstrated that RA induces the expression of miRNAs which are responsible for several tumor suppressive activities in the central nervous system. However, since the Campos group has indicated low CRABP2 expression in GBM (Campos et al. 2011), the role of miRNAs in CRABP2 regulation is still unknown. Thus, it is possible that dysregulation of miRNAs in GBM could play a role in the downregulation of CRABP2.

DNA methylation by DNA methyltransferases (DNMTs) has been reported to be a crucial type of covalent modifications of DNA. Among DNMTs, DNMT1 is a key enzyme which can maintain DNA methylation, especially through correcting methylation patterns on the new DNA strand during replication (Scott et al. 2014). Rajendran et al. (2011) have uncovered significant overexpression of DNMT1 in GBM (Rajendran et al. 2011). This emphasized the transcriptional silencing by CpG island methylation as a probable potential explanation for inactivation of several genes. Campos et al. (2012) revealed that DNA methyltransferase inhibitor 5-aza-2'deoxycytidine (5-aza) can reverse aberrant CpG methylation upstream of the CRABP2 gene locus in astrocytic gliomas (Campos et al. 2012). Therefore, DNA methylation could be one of the reasons which lead to decrease of CRABP2 in GBM cells.

Histone deacetylation is one of the posttranslational modifications in $\mathrm{N}$-terminal tails of histones and is known to regulate the expression of a whole range of genes in GBM (Cornago et al. 2014). Valproic acid (VPA), as a classic antiepileptic agent, was approved as a histone deacetylation inhibitor (HDACi) (against Class I and IIA 
HDACs), and it is already approved as treatment of several cancers (TerranovaBarberio et al. 2016, Leitch et al. 2016, Chen et al. 2009). Hosein et al. (2015) demonstrated that VPA as a therapeutic mono and in combination with TMZ and irradiation has distinct effect in primary GBM cells (Hosein et al. 2015). Moreover, as epigenetic therapy, DNMT inhibitor 5-aza with another HDAC inhibitor TSA can lead to the increase of more than 160 genes in GBM (Kim et al. 2006). However, it is still unknown whether histone deacetylation is one of the epigenetic causes resulting in CRABP2 downregulation. Thus, this study may answer the question if aberrant histone deacetylation is a potential reason causing the alteration in RA pathway particularly in downregulation of CRABP2.

SUMOylation (Muller et al. 2001) is posttranslational modification where lysine residues are covalently attached to the target protein. Majumdar et al. (2011) showed that Lysine 102 (K102) residue of CRABP2 is amino acid SUMOylated in response to RA (Majumdar et al. 2011). SUMOylation of CRABP2 enhances its translocation to the nucleus in response to RA. Therefore, conceivably the mutations in K102 would enable CRABP2 protein to lose the ability to be SUMOylated leading to its dysfunction.

\subsection{Aims of the study}

Chemoresistance remains one of the major therapeutic problems in GBM. Retinoid can induce differentiation and/or apoptosis in tumor cells and therefore has great potential as chemotherapeutic. Sometimes the use of retinoid is hindered by deregulated RA signaling, for example deregulated CRAPB2 protein is related to GBM patient's poor survival. I aimed at first to explore the potential transcriptional, posttranscriptional and posttranslational reasons for downregulation of CRABP2 protein. Further on, this study was aimed to investigate the anti-cancer mechanism of a combined application of HDACi VPA and RA on glioblastoma by evaluating their influence on the CRABP2 protein. 


\section{MATERIALS AND METHODS}

\subsection{Materials and Chemicals}

Table 1. Materials and chemicals and their sources used in the present study.

\begin{tabular}{|c|c|}
\hline Sources & Materials and Chemicals \\
\hline \multirow{2}{*}{ Bio-Rad /Hercules, USA } & SYBR-Green Mastermix \\
\hline & CFX384 cycler \\
\hline \multirow{2}{*}{ Bio-TEK Minooski, USA } & Spectrophotometer Absorption Reader \\
\hline & Synergy MX multi-mode microplate reader \\
\hline Clontech Labrotories /CA, USA & Total Human Brain RNA \\
\hline \multirow{8}{*}{ Gibco Life Technologies /Carlsbad, CA, USA } & Fetal Bovine Serum (FBS) \\
\hline & Minimum Essential Medium (MEM) \\
\hline & 0.05\% Typsin-EDTA \\
\hline & MEM Non-Essential Amino Acids (NEAA) \\
\hline & Sodium Bicarbonate Solution $7.5 \%$ \\
\hline & Sodium Pyruvate $100 \mathrm{mM}$ \\
\hline & Phosphate-Buffered Saline (PBS) pH7.4 \\
\hline & Opti-MEM medium \\
\hline GraphPad Software /La Jolla, USA & GraphPad Prism 5 \\
\hline \multirow{2}{*}{ Greiner Bio-One /Frickenhausen, Germany } & Cell Culture Flask \\
\hline & $6,12,24,96$ well Culture Plate \\
\hline \multirow{3}{*}{ Invitrogen /Carlsbad, CA, USA } & pMIR-REPORT vector \\
\hline & Lipofectamine 3000 \\
\hline & SuperScript III first-strand synthesis kit \\
\hline New England Biolab Inc. /lpswich, USA & Spel restriction enzyme \\
\hline
\end{tabular}




\begin{tabular}{|c|c|}
\hline Sources & Materials and Chemicals \\
\hline \multirow{3}{*}{ New England Biolab Inc. /lpswich, USA } & EcoR I restriction enzyme \\
\hline & $K p n$ I restriction enzyme \\
\hline & Hind III restriction enzyme \\
\hline Polysciences, Inc. Warrington, USA & Aqua Polymounting medium \\
\hline \multirow{2}{*}{ Promega, Madison, USA } & Dual-Luciferase Reporter Assay System \\
\hline & pGL4.73 Renilla luciferase vector \\
\hline \multirow{2}{*}{ Qiagen /Hilden, Germany } & Q|Azol Lysis Reagent \\
\hline & RNeasy kit \\
\hline \multirow{2}{*}{ Sarstedt /Nümbrecht, Germany } & Reagent and centrifuge tubes \\
\hline & Pipette tips \\
\hline \multirow{4}{*}{ Sigma-Aldrich/St. Louis, MO, USA } & 5-aza-2'-deoxycytidine (5-aza) \\
\hline & Vaproic acid (VPA) \\
\hline & Retinoid acid (RA) \\
\hline & Propidium iodide (PI) \\
\hline ThermoFisher Scientific /Waltham, USA & pcDNA4/myc-HisB vector \\
\hline ZEISS /Oberkochen, Germany & Axiovert 200 Fluorescence Microscopy \\
\hline
\end{tabular}

\subsection{Cell Lines}

Glioblastoma cell lines: U87MG cells were a kind gift from Julia Bode (Molecular Mechanisms of Tumor Invasion, Schaller Research Group at the University of Heidelberg and the DKFZ), and 11st, 36st, 76st, 86st, 98st, 101st, 117st cell lines were derived from patient glioblastoma samples which were developed by Christoph Schmitz-Salue from the Neurosurgery department of the Georg-August University, 
Göttingen, Germany. This study was approved by the ethical board of University Clinic Göttingen.

\subsection{Luciferase Reporter Assay}

For this assay the cells were seeded in 96-well plates at a cell density of $5 \times 10^{4}$ Human Embryonic Kidney 293 (HEK293) cells per well and incubated at $37^{\circ} \mathrm{C}$. One day later the medium was changed into Opti-MEM medium without FBS and the cells were transfected with relevant plasmids (pMIR-REPORT firefly luciferase vector or PMIR-REPORT-CRABP2-3'UTR vector together with pGL4.73 Renilla luciferase vector) as well as with hsa-mir-1262 and with hsa-mir-34a respectively in three replicates per condition (Table 2). 6-8 hours later $50 \mu \mathrm{l}$ per well medium with FBS was added. 24 hours after the transfection the cells were washed and lysed for luciferase assay according to the manufacture protocol. $20 \mu$ of cell lysate per well was mixed with $100 \mu \mathrm{l}$ of Luciferase Assay Reagent and immediately measured using luminometer from BioTek Synergy MX Monochromator-based multi-mode microplate reader.

Table 2. Cell transfection used in Luciferase Reporter Assay.

\begin{tabular}{c|c|c|c|c}
\hline Condition 1 & Condition 2 & Condition 3 & Condition 4 & Condition 5 \\
\hline $\begin{array}{c}\text { pMIR-REPORT } \\
(100 \mathrm{ng})\end{array}$ & pGL4.73 (150ng) & $\begin{array}{c}\text { PMIR-REPORT } \\
(100 \mathrm{ng})\end{array}$ & $\begin{array}{c}\text { pMIR-REPORT- } \\
\text { CRABP2-3'UTR } \\
(100 \mathrm{ng})\end{array}$ & $\begin{array}{c}\text { pMIR-REPORT- } \\
\text { CRABP2-3'UTR } \\
(100 \mathrm{ng})\end{array}$ \\
\hline & pGL4.73 (150ng) & pGL4.73 (150ng) & pGL4.73 (150ng) \\
\hline & & $\begin{array}{c}\text { hsa-mir-34a or } \\
\text { hsa-mir-1262 } \\
(10 \mathrm{pg})\end{array}$ & $\begin{array}{c}\text { hsa-mir-34a or } \\
\text { hsa-mir-1262 } \\
(10 \mathrm{pg})\end{array}$ & $\begin{array}{c}\text { mir-negative } \\
\text { control (10 pg) }\end{array}$ \\
\hline
\end{tabular}




\subsection{Construction of pcDNA4-CRABP2 plasmid and its transfection in U87MG}

Template cDNA was generated using mRNA from Total Human Brain (RNA was from \#636530, Clontech Labrotories, CA, USA) and Superscript III reverse trancriptase. The CRABP2 coding sequence was amplified by PCR using the template cDNA. The following primers were used: forward 5'-CGG AAT TCC GAT GCC CAA CTT CTC TGG C -3' and reverse 5'-GGG GTA CCC CCT CTC GGA CGT AGA CCC T -3'. The PCR product was purified on 1\% TAE agarose gel, digested with EcoRl and $K p n$ restriction enzymes and cloned into the pcDNA4/myc-HisB mammalian expression vector. The correct sequence as well as the reading frame of CRABP2 was confirmed by sequencing. U87MG cells were transfected with plasmid pcDNA4CRABP2 or pcDNA4/myc-HisB using Lipofectamine 3000 . Solution I was prepared by diluting $1.5 \mu \mathrm{l}$ Lipofectamine 3000 reagent in $25 \mu \mathrm{l}$ Opti-MEM medium. For the solution II, $1 \mu \mathrm{g}$ of DNA was diluted in $25 \mu \mathrm{l}$ Opti-MEM medium and mixed with $2 \mu \mathrm{l}$ of P3000 reagent. These two solutions were mixed, incubated for 5 minutes at room temperature and applied on the cells. After 6-8 hours, $100 \mu \mathrm{l}$ per well medium (containing FBS) was added. RT-PCR and ICC analysis were performed 24 hours after the transfection.

\subsection{Real-time Quantitative PCR}

Cellular RNA was isolated with the RNeasy kit. RNA $(1 \mu \mathrm{g})$ was reverse-transcribed into cDNA by using SuperScript III first-strand synthesis kit. CDNA (100 ng) was used for real-time PCR amplification. Real-time PCR was performed on a BioRAD CFX384 cycler using SYBR-Green Mastermix and gene-specific primers of following genes: CRABP2, FABP5, DNA methyltransferase 1 (DNMT1), Caspase 7 and Bcl-2 (Table 3). The amplification was carried out by using the following cycle protocol; $95^{\circ} \mathrm{C}$ for $15 \mathrm{~s} ; 60^{\circ} \mathrm{C}$ for $30 \mathrm{~s}$, repeating it for $40 \mathrm{X}$. Data were normalized to hydroxymethylbilane synthase (HMBS) levels. 
Table 3. Primers used for the real-time PCR.

\begin{tabular}{|c|c|c|}
\hline Gene Name & Forward Primer & Reverse Primer \\
\hline HMBS & 5'CGC ATC TGG AGT TCA GGA GTA3' & 5'CCA GGA TGA TGG CAC TGA3' \\
\hline FABP5 & 5'CCT GTC CAA AGT GAT GAT GG3' & 5'CAG CAT CAG GAG TGG GAT G3' \\
\hline CRABP2 & 5'TGC TGA GGA AGA TTG CTG TG3' & 5'CCC ATT TCA CCA GGC TCT TA3' \\
\hline $\mathrm{Bcl}-2$ & 5'TTT CTC CTG GCT GTC TCT GAA3' & 5'CCA GGG TGA TGC AAG CTC CC3 \\
\hline Caspase 7 & 5'GCT GAC TTC CTC TTC GCC TA3' & 5'CAA ACC AGG AGC CTC TTC СТ3' \\
\hline DNMT1 & 5'CGA TGT GGC GTC TGT GAG3' & 5'TGT CCT TGC AGG CTT TAC ATT3' \\
\hline
\end{tabular}

\subsection{Cell Viability Assay}

Cell viability assay was performed by using 3-(4, 5-dimethylthiazol)-2, 5diphenyltetrazolium bromide (MTT). Briefly, cells were seeded in medium with FBS in 96-well plates at a cell density of $10^{4}$ cells per well and incubated at $37^{\circ} \mathrm{C}$. After 24 hours cells were washed with $1 \mathrm{X}$ phosphate-buffered saline (1X PBS), medium without FBS was added and the cells were treated with appropriate treatments. After incubation period of 72 hours, $10 \mu \mathrm{l}$ of MTT solution was added and the cells were incubated for a further 4 hours at $37^{\circ} \mathrm{C}$. Samples were measured with a spectrophotometer absorption reader using absorbance at $562 \mathrm{~nm}$.

\subsection{Cell Proliferation Assay}

Glioblastoma cells were seeded in two replicates on 24-well poly-D-lysine-coated plates with $1 \times 10^{5}$ cells per well. The cells were treated as described in Figure 1, fixed with methanol for 20 minutes at $-20^{\circ} \mathrm{C}$, and washed three times by $1 \mathrm{X}$ PBS. Afterwards, coverslips were incubated 20 minutes in 1 X PBS containing $0.2 \%$ Triton X100 and 10\% normal horse serum, following washing three times with $\mathrm{PBS} / 1 \%$ horse serum. Then coverslips were incubated with primary antibody (anti-mouse-Ki67, 1:100, Clone MIB-1, DAKO, Glostrup, Denmark) in 1X PBS, 1\% horse serum, 
$0.2 \%$ Triton $\mathrm{X} 100$ overnight at $4^{\circ} \mathrm{C}$. Next, coverslips were washed three times with $1 \mathrm{X}$ PBS and incubated in the dark with Alexa Fluor 488 donkey anti-mouse IgG secondary antibody (1:500, Life Technologies, Carlsbad, USA) in 1X PBS with 1\% serum and $0.2 \%$ Triton $\mathrm{X} 100$ for one hour at room temperature. After washing three times with 1 X PBS, coverslips were counterstained with DAPI. At last the coverslips were dried at room temperature and mounted with Aqua Polymounting medium. The slides were examined with ZEISS Axiovert 200 Fluorescence Microscopy. The proportion of Ki-67 positive cells was counted using 20X microscopic amplification. Each treatment was performed with at least three independent experiments and each experiment was analyzed based on at least five random microscopic fields.

\subsection{Immunocytochemistry (ICC)}

Glioblastoma cells were seeded in two replicates on 24-well Poly-D-lysine-coated plates with $1 \times 10^{5}$ cells per well. The cells were treated and fixed as described above. For the staining a primary anti-goat-CRABP2 (1:50, sc-10065, Santa Cruz Biotechnology, Dallas, USA) antibody and secondary antibody Alexa Fluor 546 donkey anti-goat IgG (1:500, Life Technologies, Carlsbad, USA) were used following the above described protocol.

\subsection{Experimental design of cell treatment}

One day before the treatment $(-1)$ the glioblastoma cells were seeded in appropriate replicates already described for each performed test. On day 0 medium was aspirated, the cells were washed with $1 \mathrm{X}$ PBS and replaced with medium without FBS, in order to exclude undefined effect of the FBS medium. NC (negative control) group was treated with dimethylsulfoxide (DMSO); VPA group was treated with DMSO and VPA; V+R group was treated with VPA and RA; RA group was treated with RA. On day 1 and 2, NC and VPA groups were treated additionally with DMSO in order to mimic $R A$, which was diluted in $D M S O ; V_{+} R$ and $R A$ groups were treated with RA. On day 3, after the glioblastoma cells were treated with VPA and/or RA for 72 hours, subsequent analyses were done according to the protocol for the real-time PCR, MTT assay and ICC. 


\subsection{Statistical Analysis}

All in vitro data was performed in at least triplicate. The significance of differences was analyzed using two-sided t-tests for two-group comparisons. Calculations were performed using the statistics software GraphPad Prism 5. A probability of $P<0.05$ was considered as statistical significance. The combination index (Chou and Talalay 1984) was used to calculate the degree of drug interaction in terms of synergism or antagonism. 


\section{RESULTS}

\subsection{3'UTR of CRABP2 mRNA is not the target of hsa-mir-34a and hsa-mir-1262 in glioblastoma cells}

In recent decades non-coding RNAs such as miRNAs and long non-coding RNAs (IncRNAs) are more and more discussed in the fields of regulation of gliomas. As one of the key epigenetic gene regulation effectors, miRNAs contribute extensively to the downregulation of a wide range of target genes such as tumor suppressors and many epigenetic key enzymes in cancers. I hypothesized that miRNA could be one of the reasons causing the downregulation of CRABP2. At first the possible miRNAs which could target CRABP2, as well as their hypothetic position within 3'UTR of CRABP2 mRNA were searched through open-public microRNA database "miRwalk" (www.umm.uniheidelberg.de/apps/zmf/mirwalk/) and "miRBase" (www.mirbase.org/). The analysis revealed two miRNAs: hsa-mir-34a and hsa-mir-1262 could putatively bind CRABP2 mRNA 3'UTR (Figure 1).

A

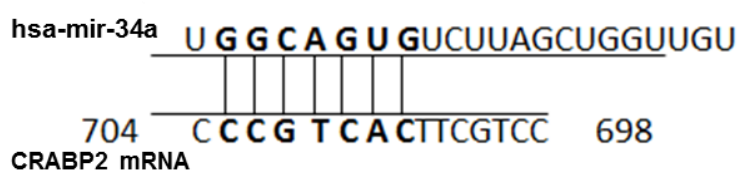

B

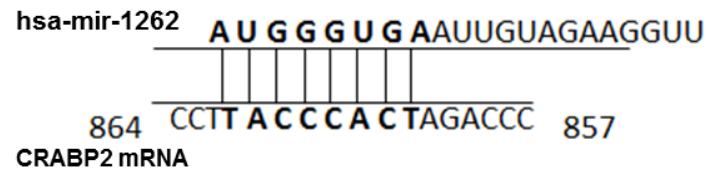

Figure 1. The hypothetic target positions of hsa-mir-34a (A) or hsa-mir-1262 (B) on CRABP2 mRNA 3'UTR according to microRNA database "miRwalk" and "miRBase".

Furthermore, in order to check the expression of these miRNAs in low grade gliomas compared to GBM I used "The Cancer Genome Atlas (TCGA) Data Portal" (by National Cancer Institute and National Human Genome Institute). I found that hsamir-34a and hsa-mir-1262 are significantly higher expressed in glioblastomas $(n=17)$ compared to the one in low grade gliomas $(n=17)(p=0.0438, p=0.0057)$ (Figure 2 and 3). 


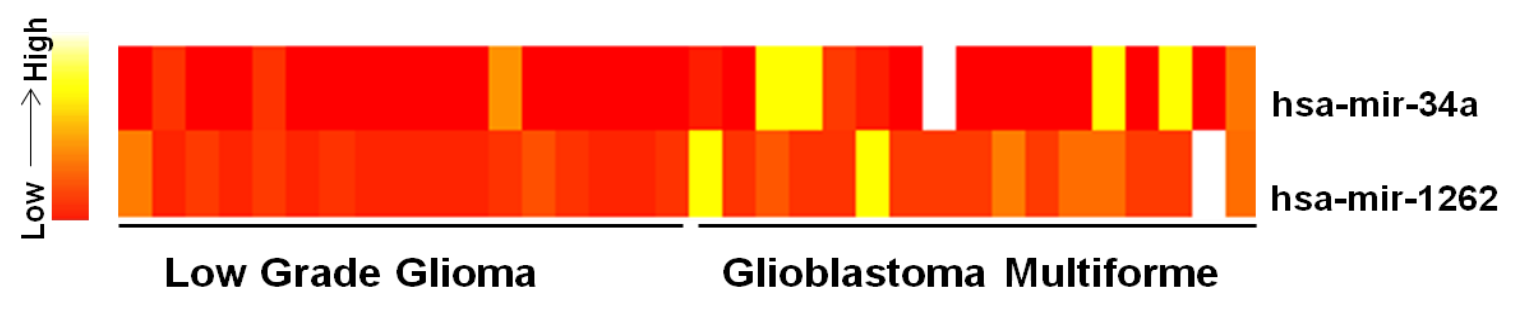

Figure 2. Heat map presenting the expression profiles of hsa-mir-34a and hsa-mir-1262 respectively in 17 low grade gliomas and 17 GBM tissues (original microarray data from TCGA).

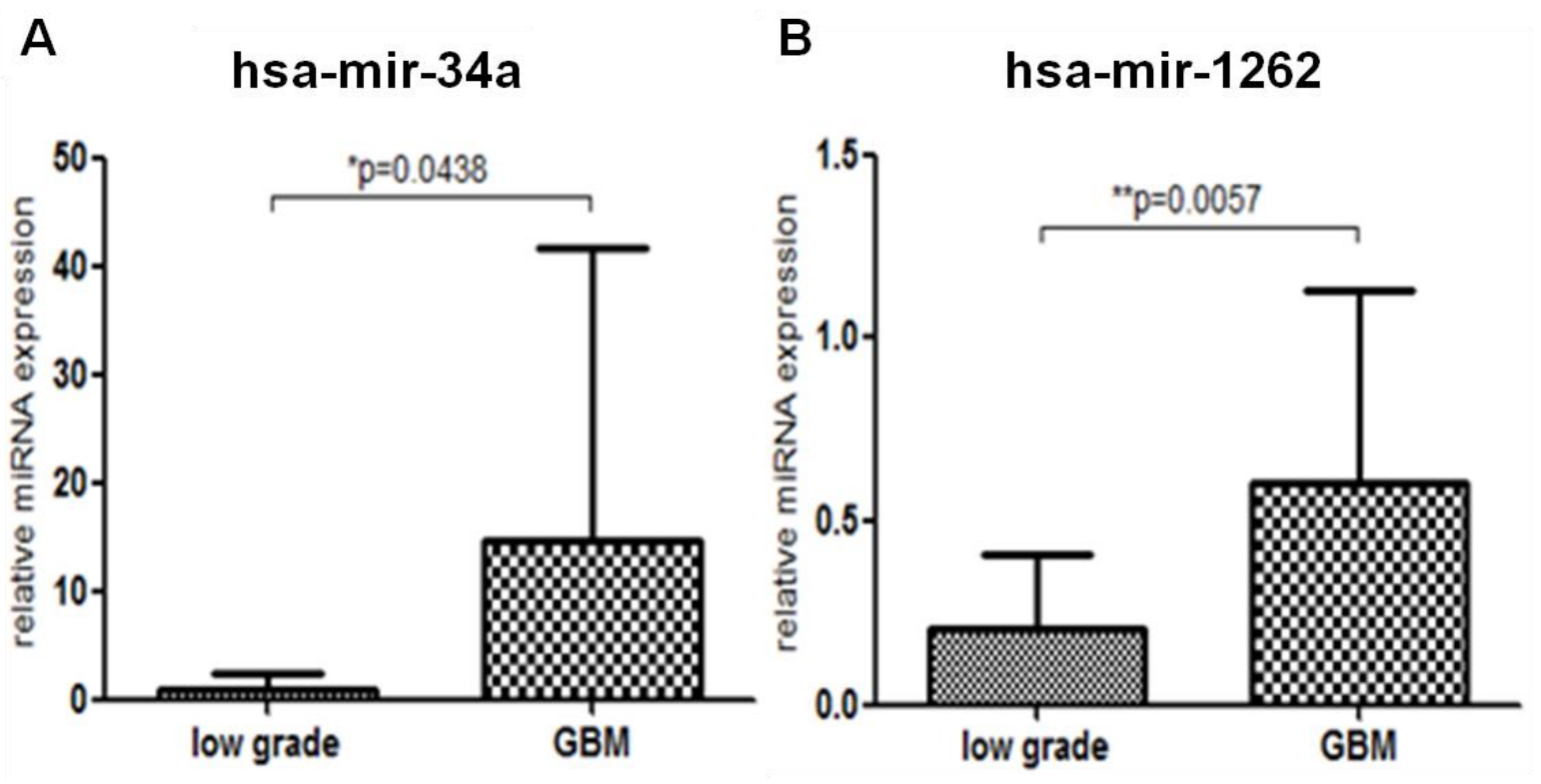

Figure 3. Real-time PCR analysis of data from TCGA showed that hsa-mir-34a (A, $\mathrm{p}=0.0438)$ and hsa-mir-1262 ( $\mathrm{B}, \mathrm{p}=0.0057)$ were increased significantly in 17 low grade gliomas compared to $17 \mathrm{GBM}$ tissues. Bars depict mean \pm S.E.M. from three independent experiments. Statistical analysis was performed using two-sided t-tests for two-group comparisons $\left({ }^{\star} \mathrm{P}<0.05,{ }^{\star \star} \mathrm{P}<0.01\right)$.

In order to determine the effect of miRNAs on the activity of CRABP2-3'UTR luciferase assays were performed in HEK293 cells. Human brain total RNA was used to generate cDNA by reverse transcription. This CDNA was used as a template to amplify CRABP2-3'UTR. PCR product was purified from the gel, cut with HindII and 
Spel restriction enzymes and ligated into the pMIR-REPORT (Figure 4 A) firefly luciferase vector. pMIR-REPORT -CRABP2-3'UTR (Figure 4 B) vector was cotransfected with pGL4.73 (Figure $4 \mathrm{C}$ ) renilla luciferase vector, as well as hsa-mir1262 and hsa-mir-34a respectively, in HEK293 cells. The luciferase activities of the cells co-transfected with pMIR-REPORT-CRABP2-3'UTR and hsa-mir-34a or hsamir-1262 did not show any significant differences compared with control groups. This suggests that in these trials, hsa-mir-34a and hsa-mir-1262 do not target CRABP2 3'UTR region and are not responsible for posttranscriptional degradation of CRABP2 in glioblastomas.
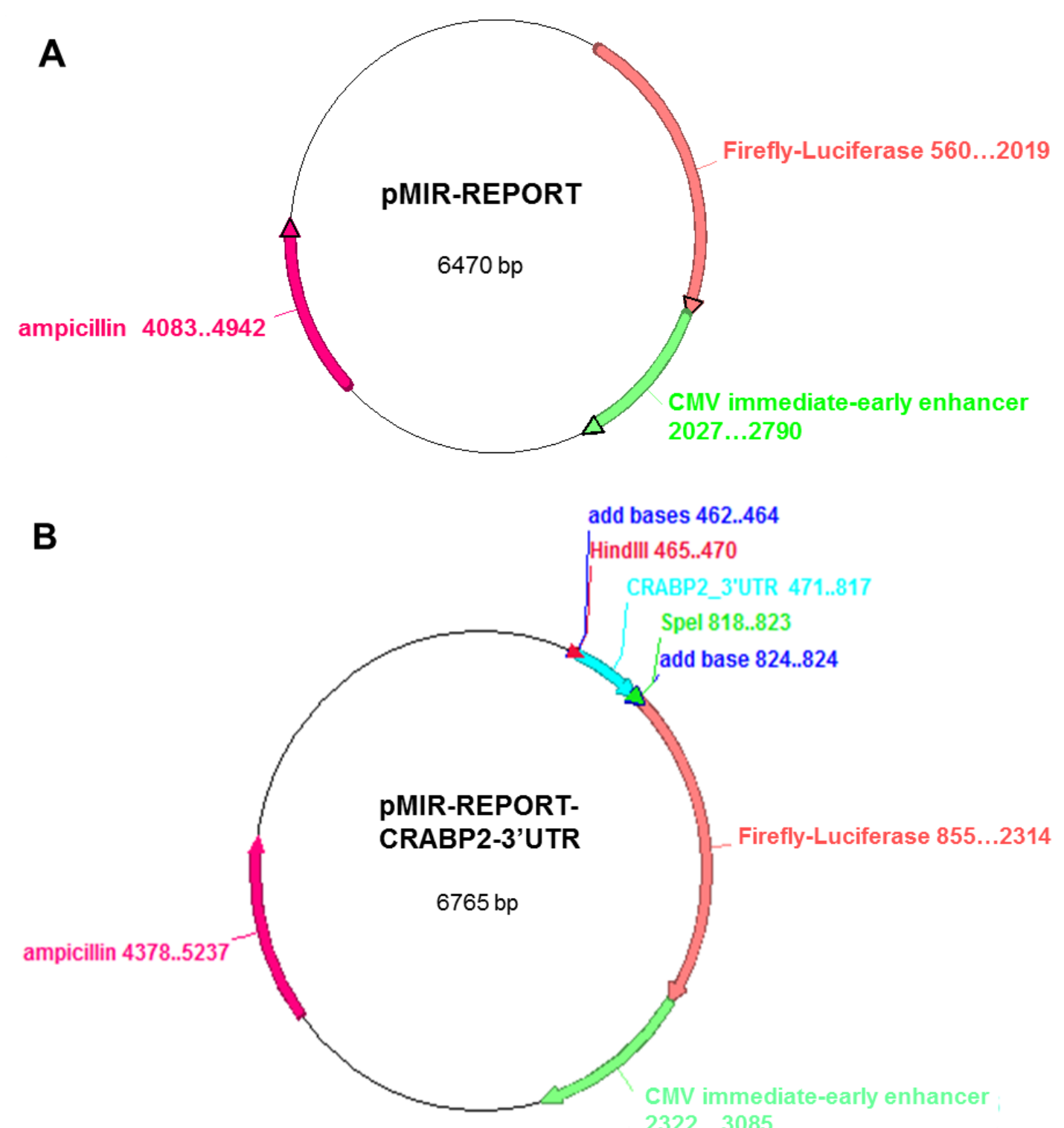


\section{C}

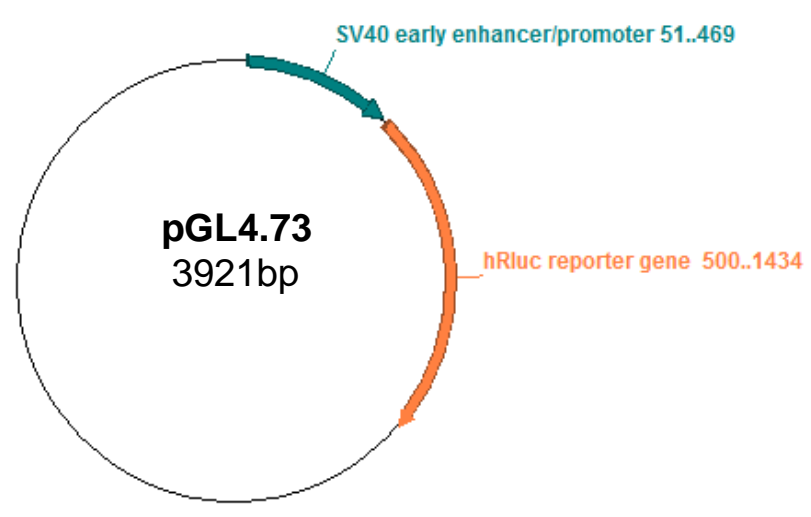

Figure 4. The commercially available pMIR-REPORT (A) firefly luciferase vector and pGL4.73 (C) renilla luciferase vector and pMIR-REPORT-CRABP2-3'UTR firefly luciferase vector (B) which was constructed according to Hindll-Spel restriction sites and CRABP2 mRNA 3'UTR sequence.

\subsection{Downregulation of CRABP2 protein in glioblastomas is not due to the mutation in Lysine 102}

Majumdar et al. showed that E2SUMO ligase Ubc9 interacts with CRABP2 and hence SUMOylates the CRABP2 protein. Lysine 102 (K102), as one of three putative SUMOylation sites of CRABP2, is SUMOylated and is essential for the mobilization of CRABP2 protein into nucleus and its delivery of RA to RAR-RXR transcriptional activation.

Protein and mRNA expression analysis from 10 GBM tissues, 7 cell lines derived from glioblastoma patients tissue; 11st, 36st, 76st, 86st, 98st, 101st, 117st and from U87MG commercially available cell line showed low CRABP2 expression (data not shown). In order to check if the eventual mutation in K102 is the reason for its downregulation, at first, we extracted mRNAs of these samples and generated cDNA using reverse transcriptase. These cDNAs were used to amplify CRABP2 product (showed in Materials and Methods) by PCR and to clone it in to pGEM-T Easy Vector. DNA from these samples was amplified and sequenced using pGEM-T Easy specific primers. I could not detect any mutation in sequence coding for $\mathrm{K} 102$ 
residue, the amino acid responsible for SUMOylation of CRABP2 and mobilization of the CRABP2 protein into the nucleus.

\subsection{Effect of combined VPA and RA treatment on CRABP2 expression in GBM cells}

Histone deacetylation is known as one of the epigenetic modifications by which expression of many genes were regulated in GBM. Here we showed that treatment of U87MG and patient-derived 36st glioblastoma cells with VPA (10 mM) upregulates CRABP2 expression. Detailed experimental design of treatment according to time procedure is described in Figure 5.

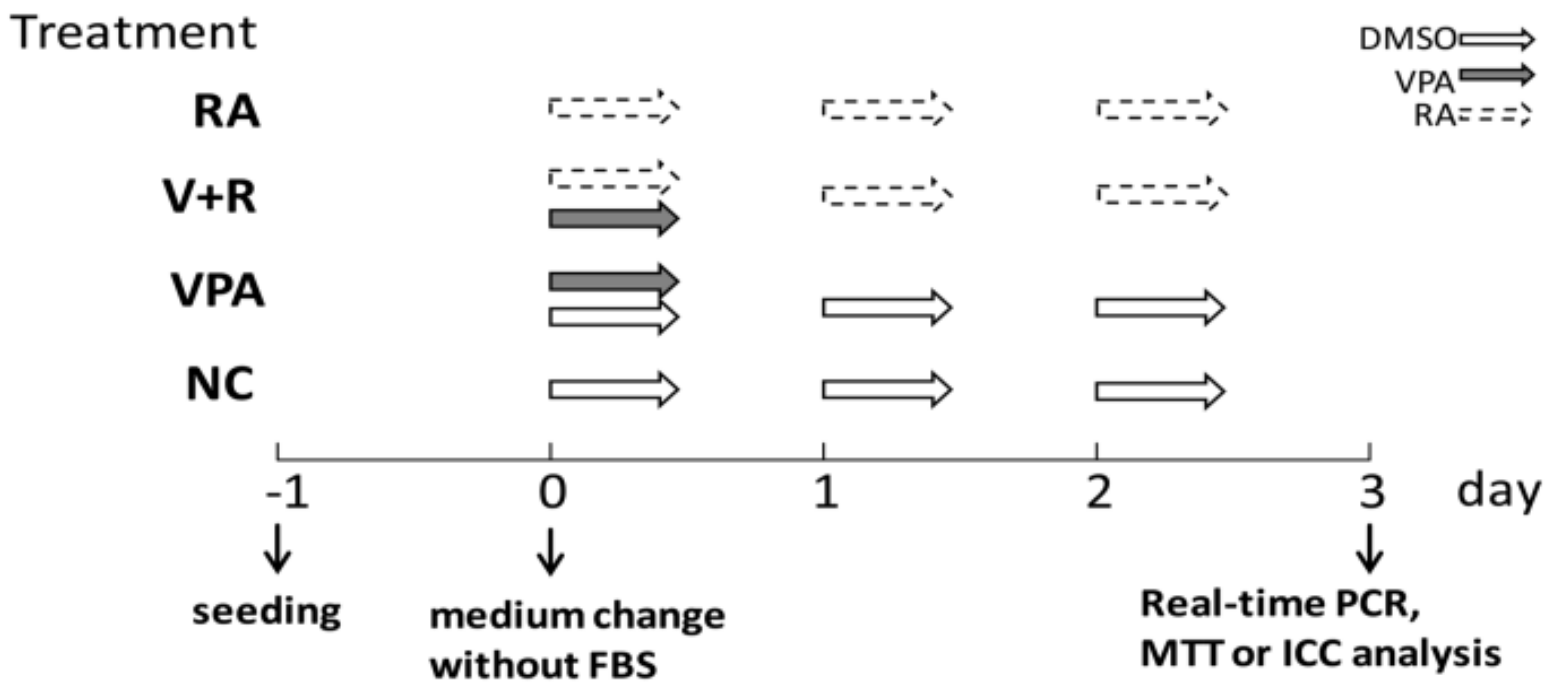

Figure 5. Schematic presentation of the experimental design. One day before the treatment $(-1)$ the glioblastoma cells were seeded in appropriate replicates. On day 0 , NC group was treated with DMSO; VPA group was treated with DMSO and VPA; V+R group was treated with VPA and RA; RA group was treated with RA. On day 1 and 2, NC and VPA groups were treated with DMSO; $V+R$ and RA groups were treated with $R A$. On day 3 , after 72 hours of treatment, subsequent analyses were done accordingly to the protocol for the Real-time PCR, MTT assay and ICC. MTT: 3-(4,5-Dimethylthiazol-2-yl)-2,5-diphenyltetrazolium bromide; ICC: Immunocytochemistry; VPA: Valproic acid, with $2 \mathrm{mM}, 5 \mathrm{mM}, 10 \mathrm{mM}$ respectively; RA: Retinoic acid, with $5 \mu \mathrm{M}$. 
Even though CRABP2 mRNA expression was increased after VPA, significant upregulation ( $p=0.0094, p=0.0408$ ) was achieved using $V+R$ treatment for three days in U87MG and 36st glioblastoma cells (Figure 6).

U87MG CRABP2

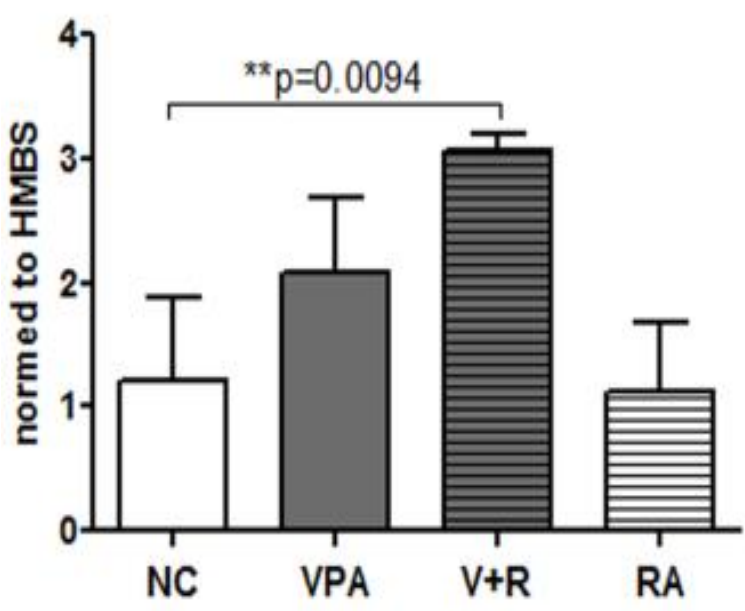

36st CRABP2

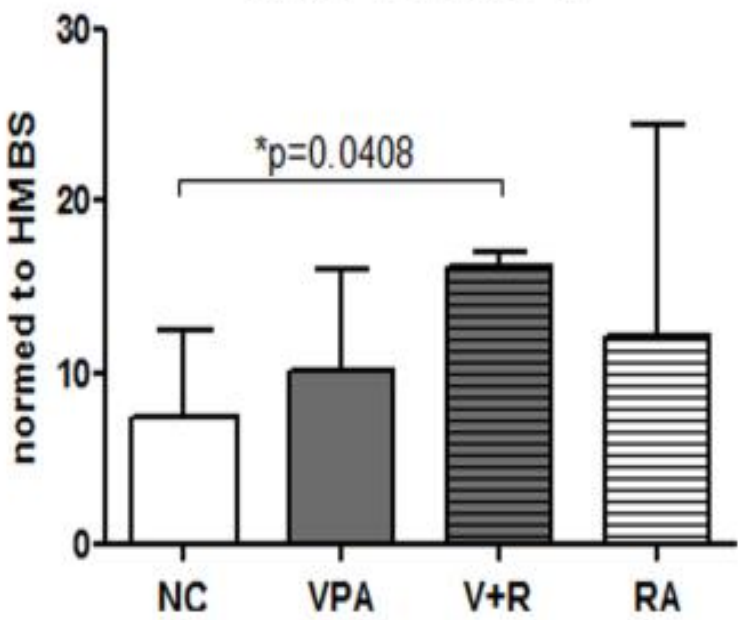

Figure 6. Real-time PCR analysis showed that CRABP2 expression was increased significantly after combined VPA $(10 \mathrm{mM})$ and RA $(5 \mu \mathrm{M})$ treatment for three days, in U87MG (left, $p=0.0094$ ) and 36st (right, $p=0.0408$ ) GBM cells. Bars depict mean \pm S.E.M. from three independent experiments. Statistical analysis was performed using two-sided t-tests for twogroup comparisons $\left({ }^{*} \mathrm{P}<0.05,{ }^{*} \mathrm{P}<0.01\right)$.

Moreover, the ratios of FABP5/CRABP2 in these treatment groups were consequently downregulated, as showed by analysis of real-time PCR results, in which $\mathrm{V}+\mathrm{R}(\mathrm{p}=0.0160, \mathrm{p}=0.0493)$ groups revealed notably reduction in U87MG and 36st cells (Figure 7). 
U87MG

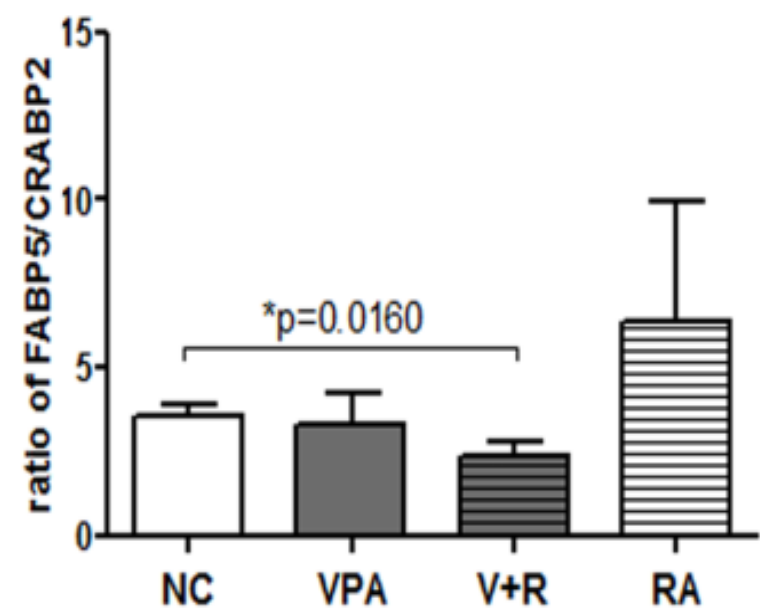

36 st

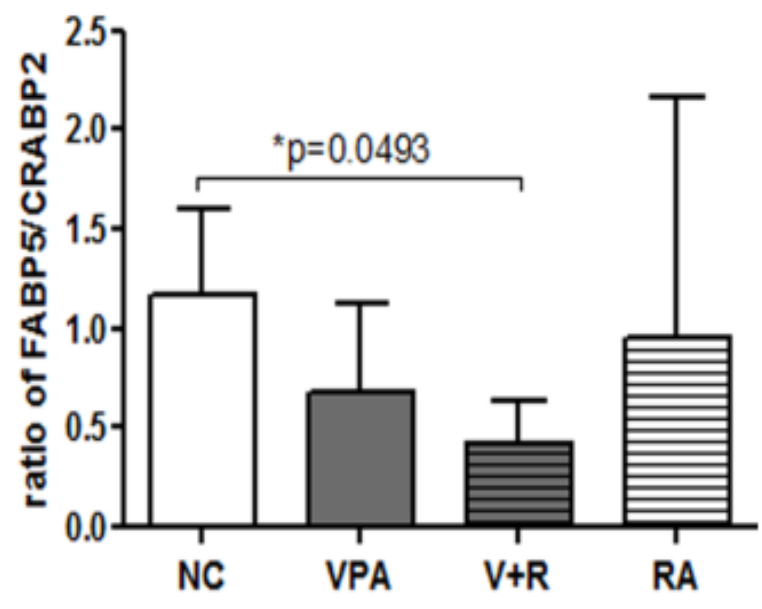

Figure 7. Real-time PCR analysis showed that the ratios of FABP5/CRABP2 were decreased in $\mathrm{V}+\mathrm{R}$ group in U87MG (left, $\mathrm{p}=0.0160$ ) and 36st cells (right, $p=0.0493$ ). Bars depict mean \pm S.E.M. from three independent experiments. Statistical analysis was performed using two-sided t-tests for two-group comparisons $\left({ }^{*} \mathrm{P}<0.05\right)$.

Furthermore, ICC experiments not only supported that VPA and V+R treatment can increase CRABP2 protein expression in glioblastoma cells (Figure $8 \mathbf{A}$ and $\mathbf{C}$ ), but also revealed different cellular localization of this protein. Treatment of these GBM cells with VPA shows cytoplasmic localization of CRABP2 protein, where $\mathrm{V}+\mathrm{R}$ groups show more nuclear localization (Figure 8 B and D). Given that CRABP2 is one of the key RA transport-proteins, CRABP2 with more nuclear localization in $\mathrm{V}+\mathrm{R}$ groups suggested more RA-pathway-related molecules were activated in cell nucleus in vitro. 

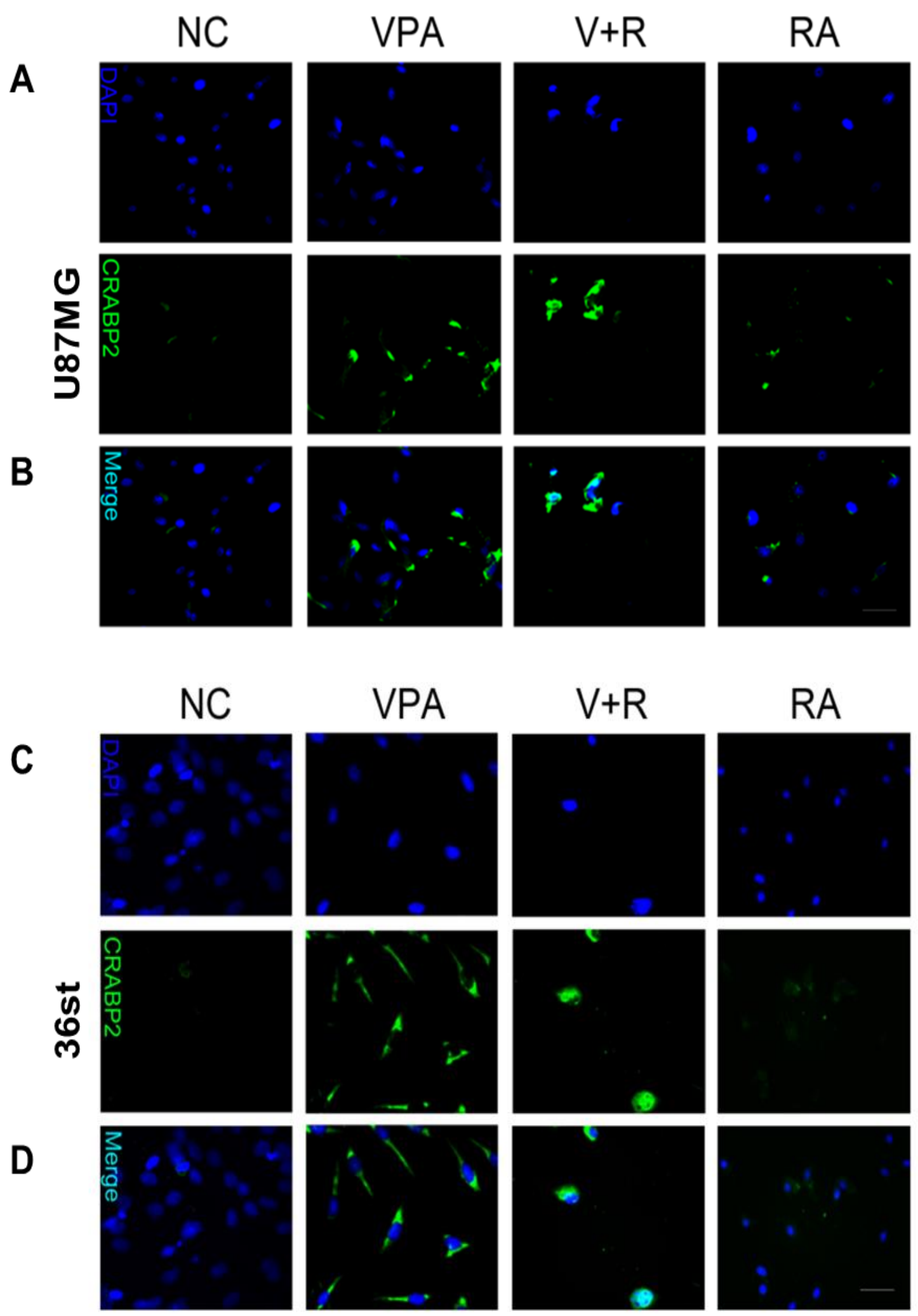

Figure 8. VPA in combination with RA upregulate CRABP2 expression in GBM cells. ICC experiments showed that VPA, $\mathrm{V}+\mathrm{R}$ treatment can increase CRABP2 protein expression in U87MG (A) and 36st (C) glioblastoma cells. $B$. and D. VPA and $V+R$ groups revealed 
different cellular localization of CRABP2 proteins. Treatment of U87MG (B) and 36st (D) cells with VPA showed cytoplasmic localization of CRABP2 protein, where $V+R$ group showed more nuclear localization. The scale bar is $50 \mu \mathrm{m}$.

\subsection{VPA treatment alone and in combination with RA inhibit proliferation and} cell viability of GBM cells

Next we tested the proliferation ability of GBM cells under VPA and RA treatments. It is already known that VPA can inhibit proliferation of GBM cells in vitro. Staining of both cell lines with anti-Ki-67 antibody (cellular proliferation marker) showed less Ki67 stained cells after treatment with 10 mM VPA. Yet again, the combination of both drugs showed a stronger inhibition of the proliferation compared with single treatment (Figure 9 A and B).

A
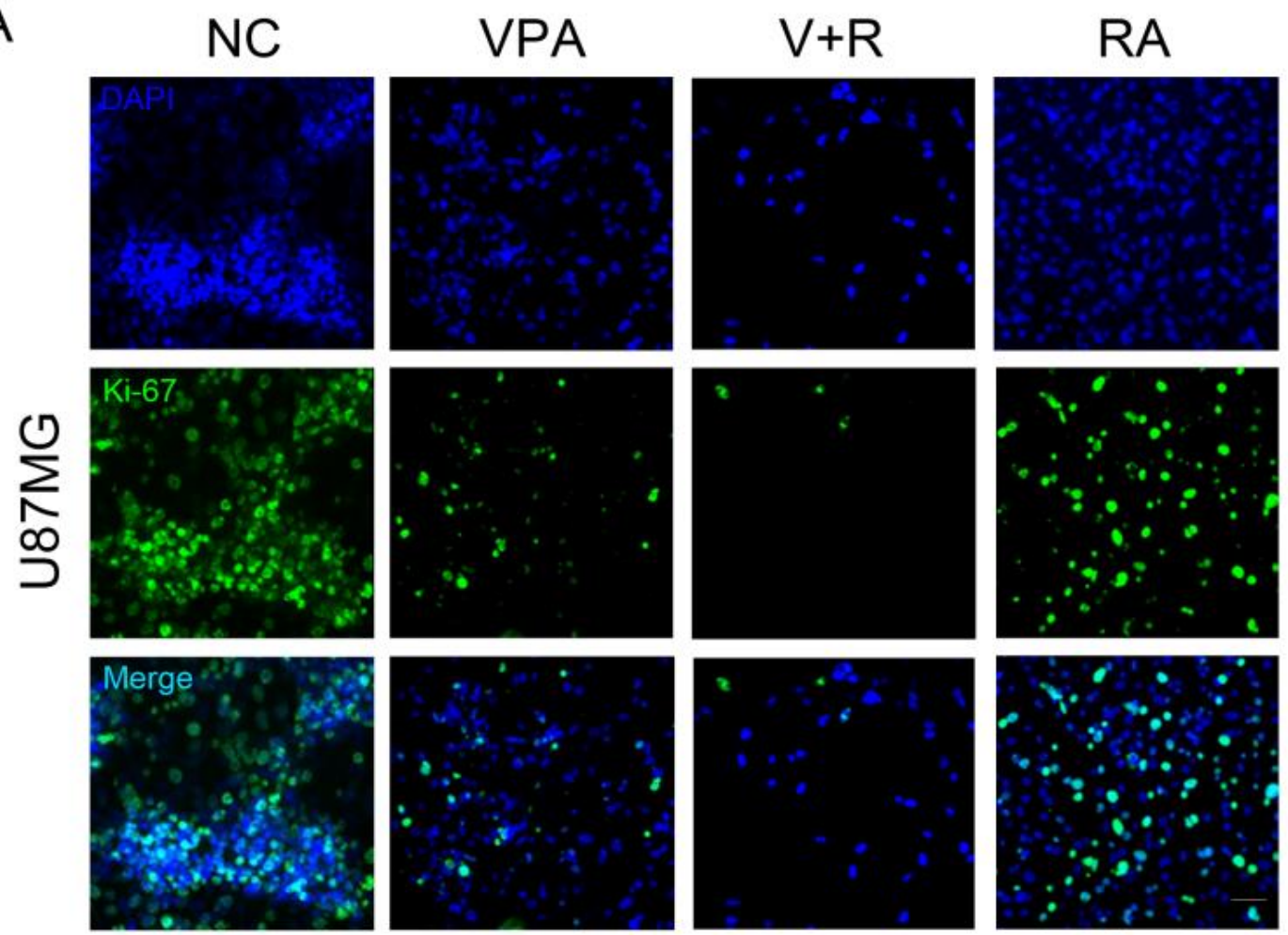
B
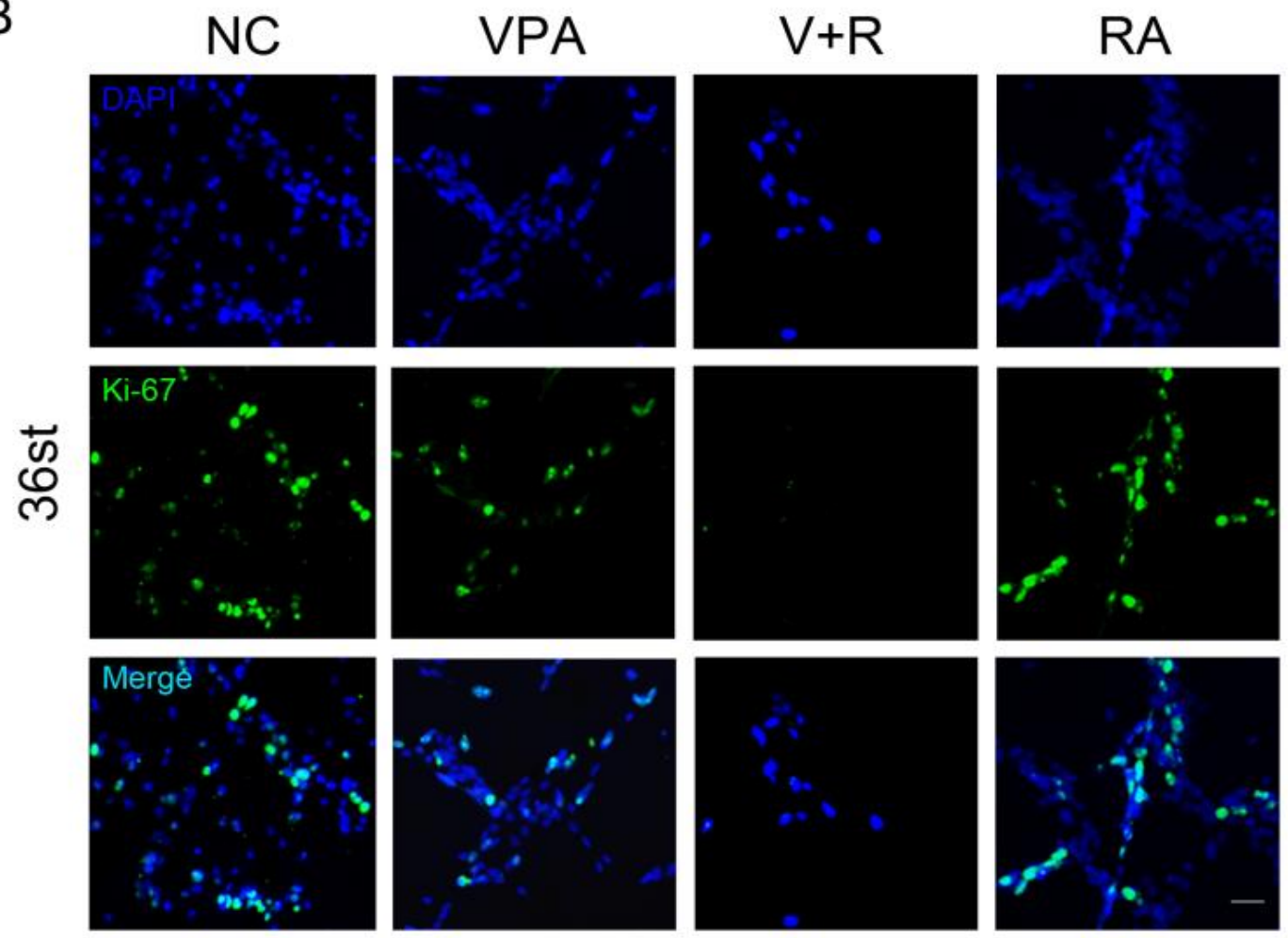

Figure 9. VPA treatment alone and in combination with RA inhibits proliferation and cell viability of GBM cells. A and B Cell proliferation assay showed less Ki-67 (cellular proliferation marker) stained cells after treatment with $10 \mathrm{mM}$ VPA. Furthermore, combination $\mathrm{V}+\mathrm{R}$ showed stronger inhibition of the proliferation compared with single treatment in both U87MG (A) and 36st (B) cell lines. The scale bar is $100 \mu \mathrm{m}$.

Furthermore, it was found that combined treatment with VPA and RA synergistically decreases the proliferation, since the proportion of Ki-67 positive cells was considerably lower compared with $\mathrm{NC}(\mathrm{p}=0.0009, \mathrm{p}=0.0025)$ or VPA single treatment group ( $p=0.0172, p=0.0327$ ) (Figure 10). 

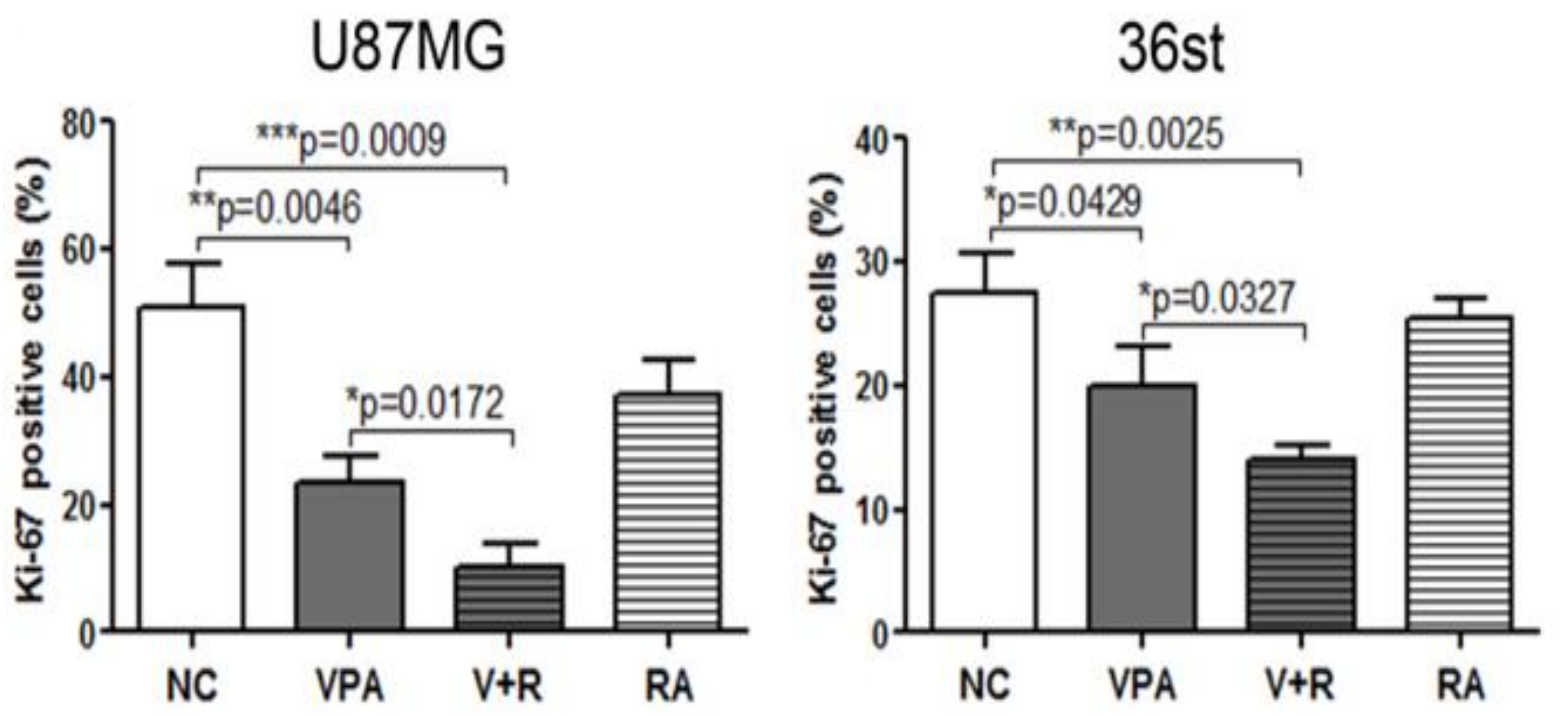

Figure 10. The proportion of Ki-67 positive cells in $\mathrm{V}+\mathrm{R}$ groups were considerably lower compared with NC $(p=0.0009, p=0.0025)$ or VPA single treatment group $(p=0.0172$, $\mathrm{p}=0.0327$ ) in U87MG (left) and 36st (right) cell lines. Cell Proliferation Assays with anti-Ki-67 antibody were performed at least in three independent experiments in both cell lines. Bars depict mean \pm S.E.M. from three independent experiments. Statistical analysis was performed using two-sided t-tests for two-group comparisons $\left({ }^{*} \mathrm{P}<0.05, \quad{ }^{* *} \mathrm{P}<0.01\right.$, $\left.{ }^{* * *} \mathrm{P}<0.001\right)$.

Using MTT assay it was shown that the cell viability in U87MG $(p=0.0115)$ and 36st $(p=0.0432)$ was inhibited after 72 hours treatment with VPA (Figure 11). Similarly in MTT assay, $V+R$ group showed a very strong decrease in cell viability compared to both control $(p<0.0001, p=0.0006)$ and VPA single $(p=0.0115, p=0.0006)$ treatment (Figure 11). 

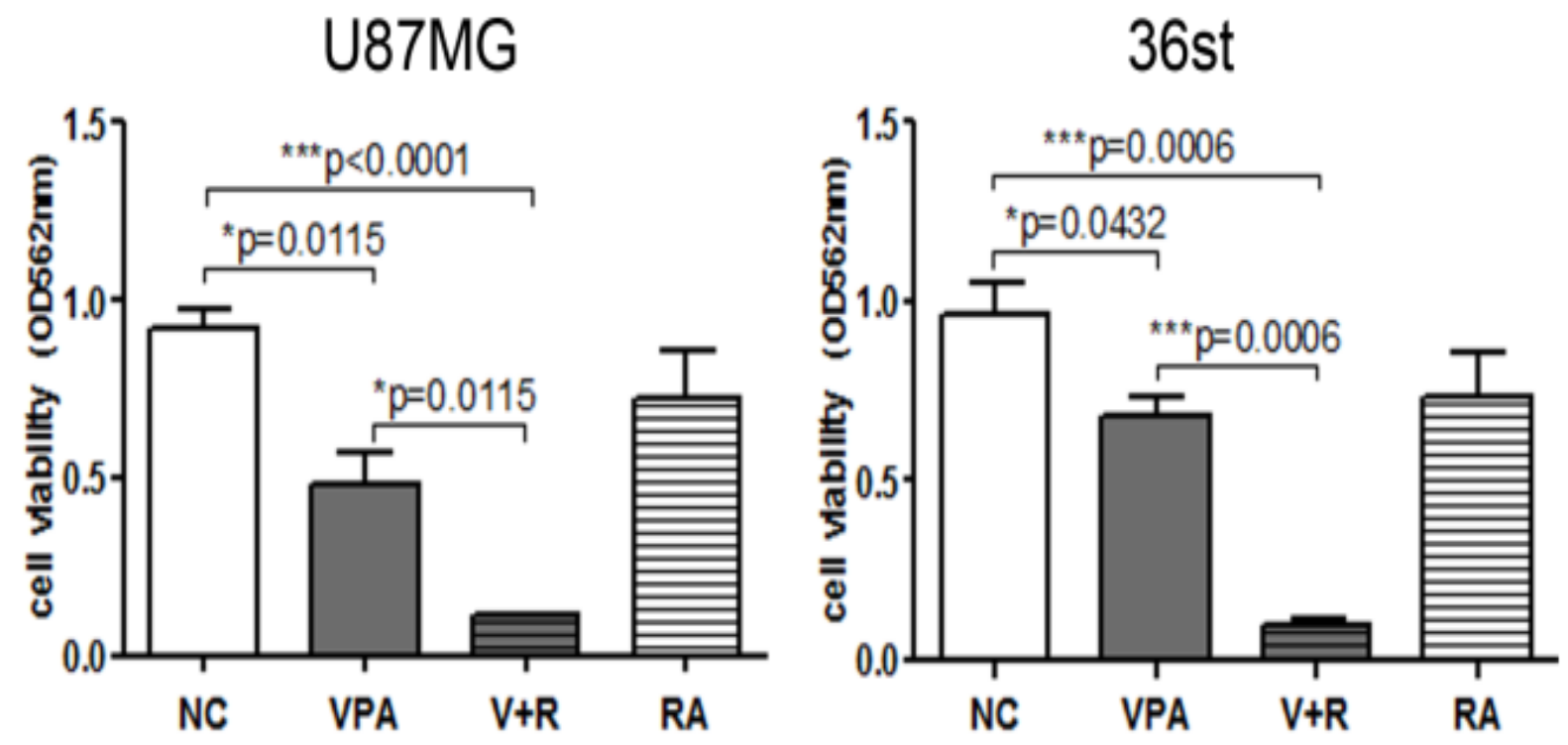

Figure 11. The cell viability in U87MG (left, $p=0.0115$ ) and 36st (right, $p=0.0432$ ) was inhibited after 72 hours treatment with VPA alone. Furthermore, V+R group showed significant higher decrease in cell viability comparing to both, control and VPA single treatment. Bars depict mean \pm S.E.M. from three independent experiments. Statistical analysis was performed using two-sided t-tests for two-group comparisons $\left({ }^{*} \mathrm{P}<0.05\right.$, $\left.{ }^{* *} \mathrm{P}<0.01,{ }^{* * *} \mathrm{P}<0.001\right)$.

Besides this, the reduction of VPA concentration up to $2 \mathrm{mM}$ in combination with RA was still able to show significant effect on U87MG and 36st cell lines (Figure 12 A and B) in MTT assays. More specifically, MTT assay showed that the cell viability in U87MG and 36st was inhibited with V2+R $(p=0.0018, p=0.0277)$ and $V 5+R$ $(p=0.0005, p=0.0124)$ treatment compared to control groups in both cell lines (Figure 12 B). 

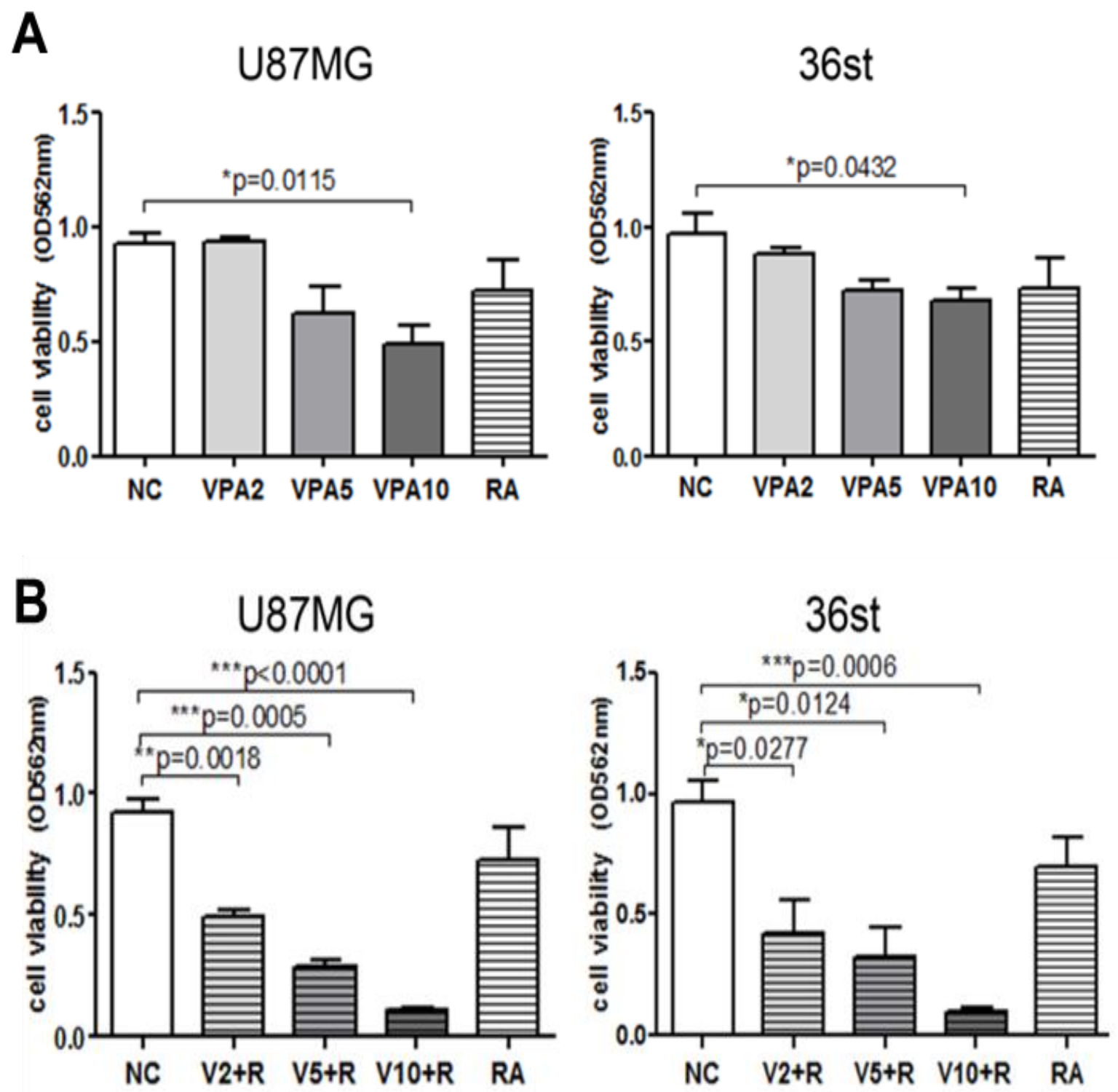

Figure 12. The reduction of VPA concentration up to $2 \mathrm{mM}$ in combination with RA was still able to cause significant reduction in cell viability in U87MG (left) and 36st (right) cell lines. VPA10: $10 \mathrm{mM}$; VPA5: $5 \mathrm{mM}$; VPA2: $2 \mathrm{mM}$. Bars depict mean \pm S.E.M. from three independent experiments. Statistical analysis was performed using two-sided t-tests for twogroup comparisons $\left({ }^{*} \mathrm{P}<0.05,{ }^{* *} \mathrm{P}<0.01,{ }^{* *} \mathrm{P}<0.001\right)$.

\subsection{VPA treatment as well as DNA methylation Inhibitor 5-aza decrease DNMT1 levels in GBM cells}

DNA methylation leads to downregulation of CRABP2 on transcriptional level. Since DNMT1 plays a key role maintaining DNA methylation, VPA influence on transcription 
of this enzyme was examined. Firstly, DNA methylation inhibitor 5-aza was used in concentration of $2 \mu \mathrm{M}$ or $10 \mu \mathrm{M}$ for three days in order to confirm the influence of DNA methylation on CRABP2 in U87MG glioblastoma cells. The results of real-time PCR showed that $10 \mu \mathrm{M}$ of 5 -aza significantly increased $(p=0.0444)$ the expression of CRABP2 mRNA in U87MG cell lines (Figure 13).

\section{U87MG CRABP2}

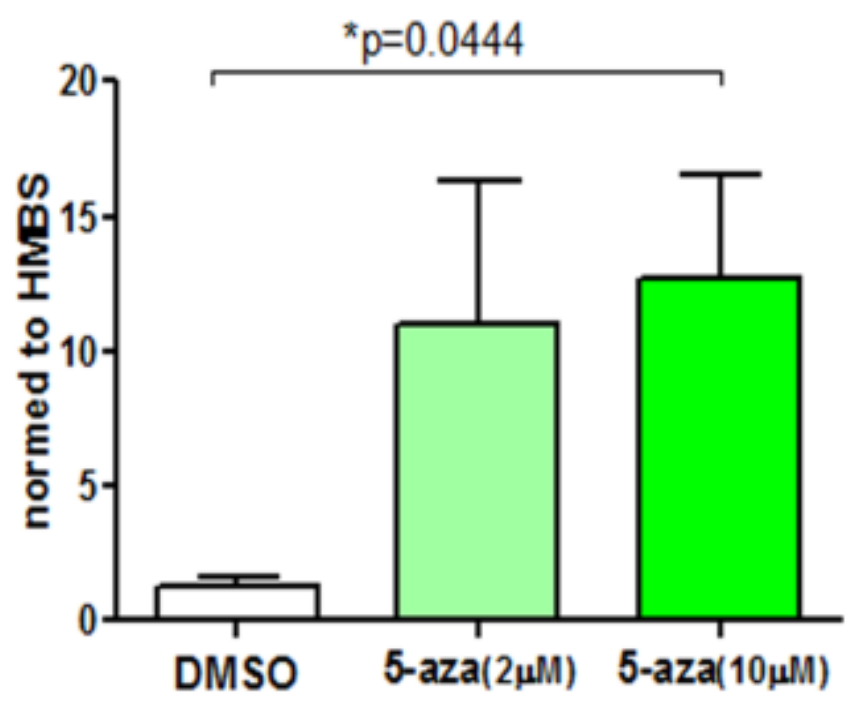

Figure 13. The real-time PCR showed that $10 \mu \mathrm{M}$ DNA methylation inhibitor 5-aza significantly increased $(p=0.0444)$ the expression of CRABP2 mRNA in U87MG cell lines. Data were normalized to hydroxymethylbilane synthase (HMBS) levels. Bars depict mean \pm S.E.M. from three independent experiments. Statistical analysis was performed using twosided t-tests for two-group comparisons ( $\left.{ }^{*} \mathrm{P}<0.05\right)$.

Besides this, decreased cell viability was detected by MTT assay under the treatment of the U87MG with $10 \mu \mathrm{M} 5$-aza alone $(\mathrm{p}=0.0422)$ and $10 \mu \mathrm{M}$ 5-aza combined with $5 \mu \mathrm{M} R A(p=0.0434)$ (Figure 14). 


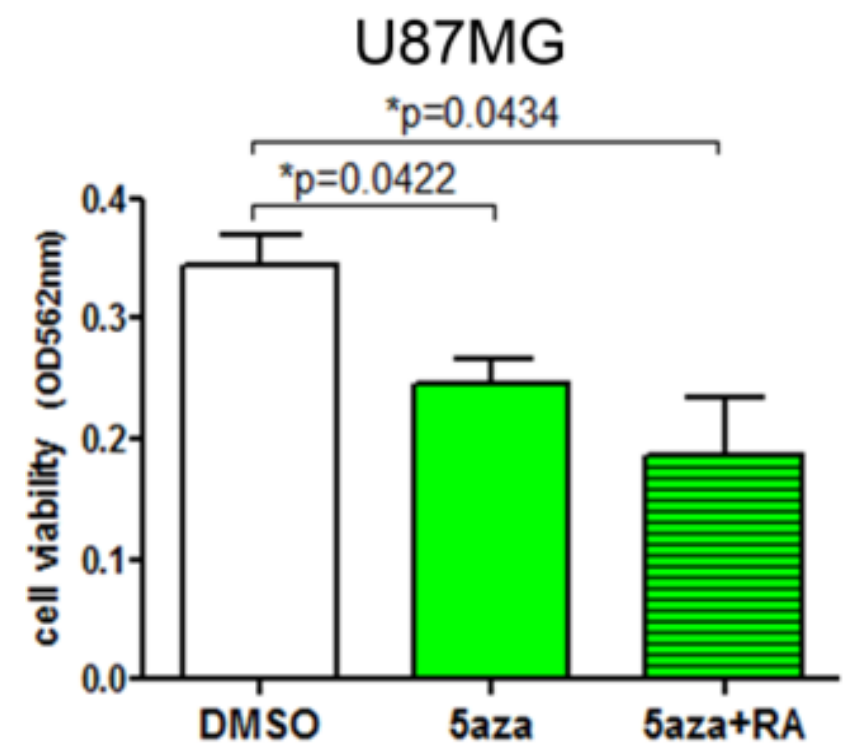

Figure 14. U87MG cell viability decreased notably in MTT assay by treatment with $10 \mu \mathrm{M} 5$ aza $(p=0.0422)$ and $10 \mu \mathrm{M} 5$-aza combined with $5 \mu \mathrm{M} R A(p=0.0434)$. Bars depict mean \pm S.E.M. from three independent experiments. Statistical analysis was performed using twosided t-tests for two-group comparisons ( $\left.{ }^{*} \mathrm{P}<0.05\right)$.

The real-time PCR results showed that treatment of GBM cells with VPA and V+R prominently downregulated the expression of DNMT1 in both U87MG $(p=0.0359$, $p=0.0484)$ and patient-derived 36st $(p=0.0002, p=0.0021)$ GBM cell lines (Figure 15).
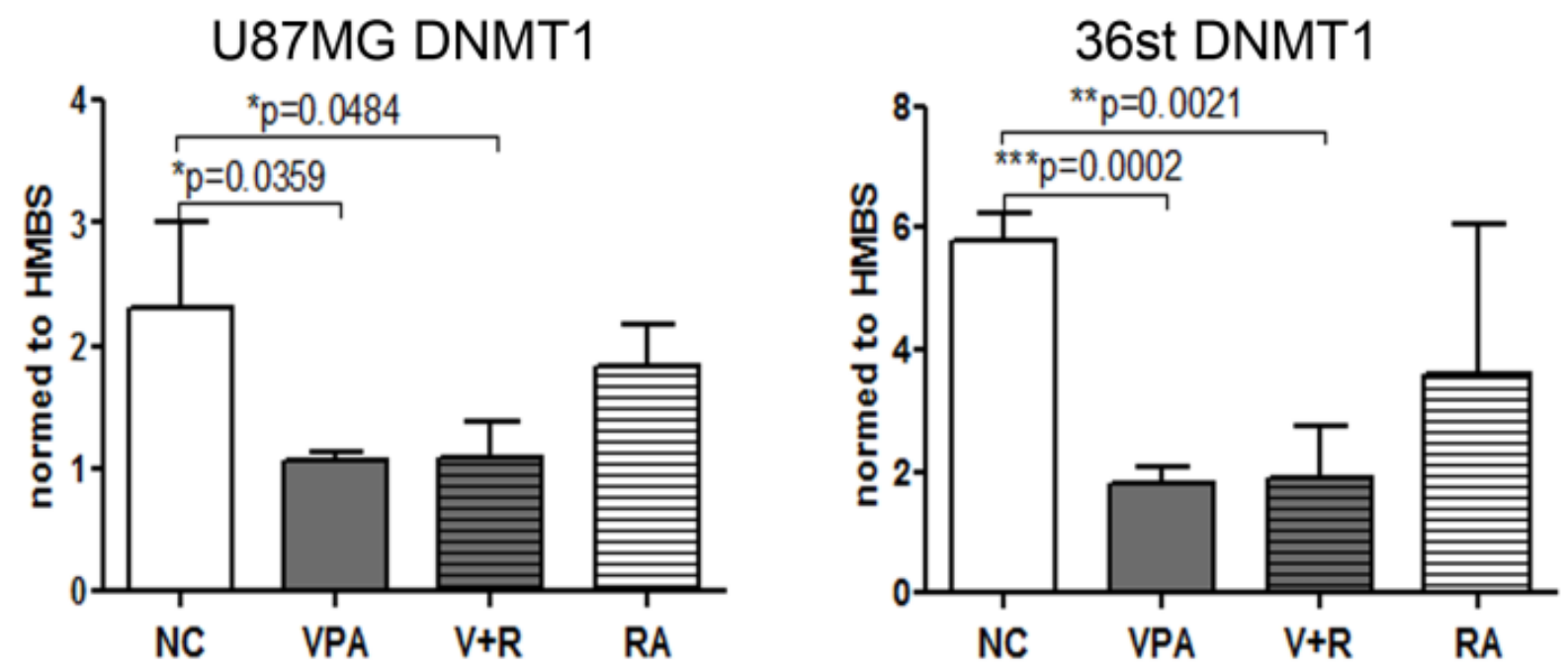

Figure 15. VPA treatment decreases DNMT1 levels in GBM cells. Bars depict mean \pm S.E.M. from three independent experiments. Statistical analysis was performed using two-sided ttests for two-group comparisons $\left({ }^{*} \mathrm{P}<0.05,{ }^{* \star} \mathrm{P}<0.01,{ }^{* *} \mathrm{P}<0.001\right)$. 


\subsection{Overexpression of CRABP2 as well as VPA treatment increase apoptosis in} vitro

In order to prove the specific effect of CRABP2 on GBM cells we transfected pcDNA4-CRABP2 plasmid (Figure 16 B) in U87MG cell lines. The coding sequence of CRABP2 has been cloned with the correct reading frame in the expression plasmid pcDNA4/myc-HisB (Figure 16 A) using EcoRl-Kpnl restriction sites. Transfection of U87MG GBM cells with pcDNA4-CRABP2 plasmid increased cell death as detected by immunofluorescence staining with propidium iodide (PI), (Figure 17).

A

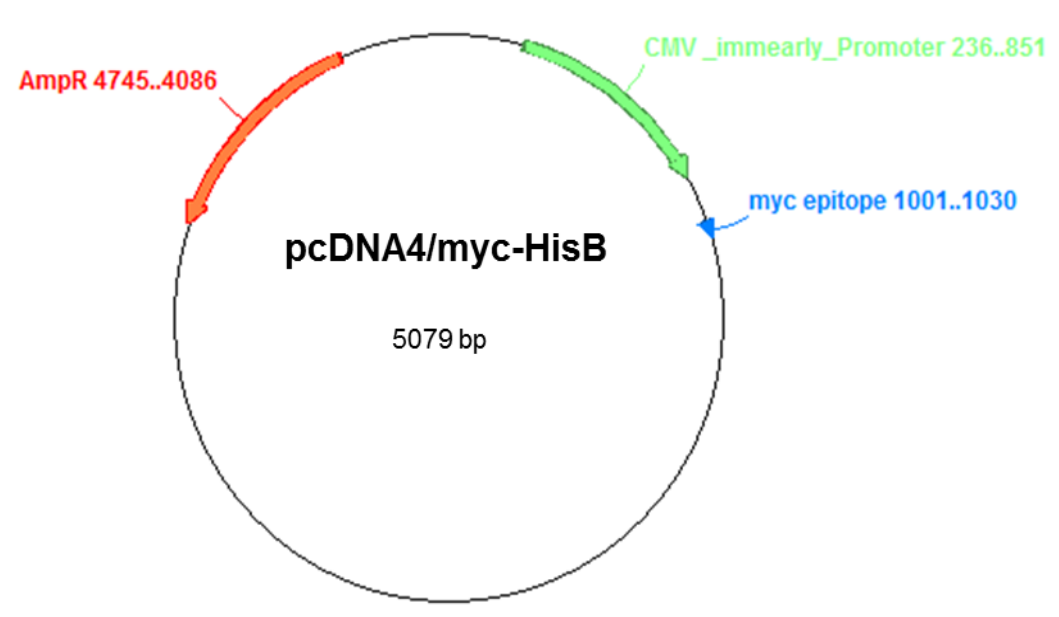

B

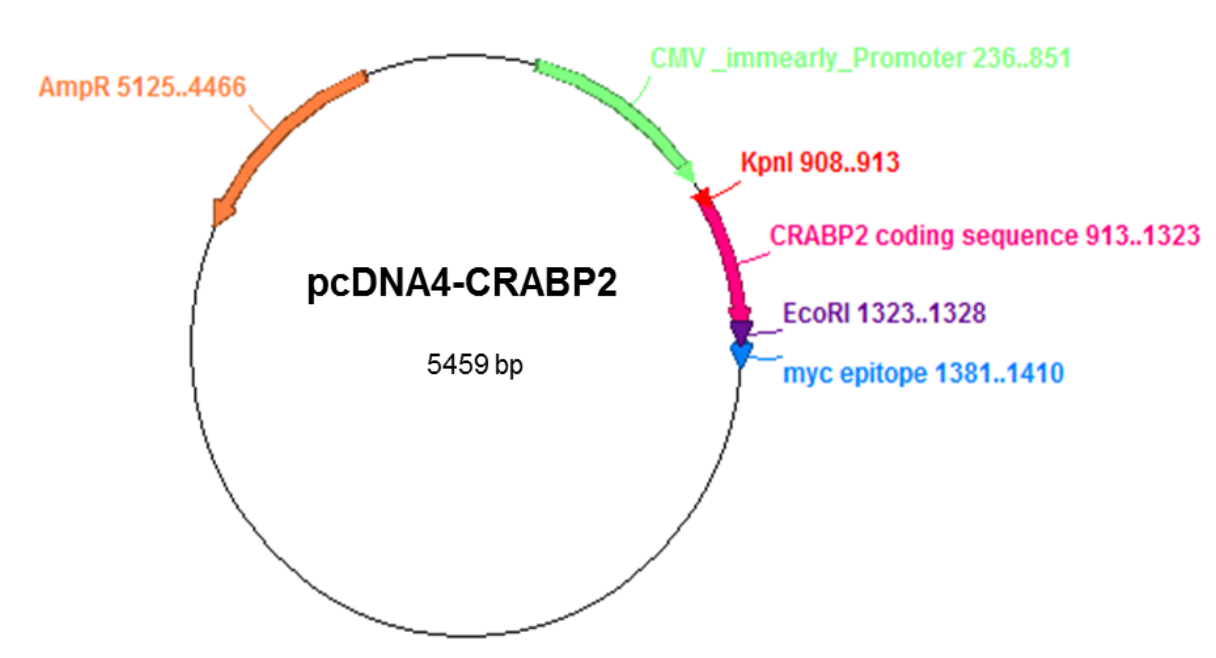

Figure 16. The commercially available pcDNA4/myc-HisB plasmid (A), and constructed pcDNA4-CRABP2 plasmid (B) CRABP2 coding sequence was cloned using EcoRl-Kpnl restriction sites. 
U87MG

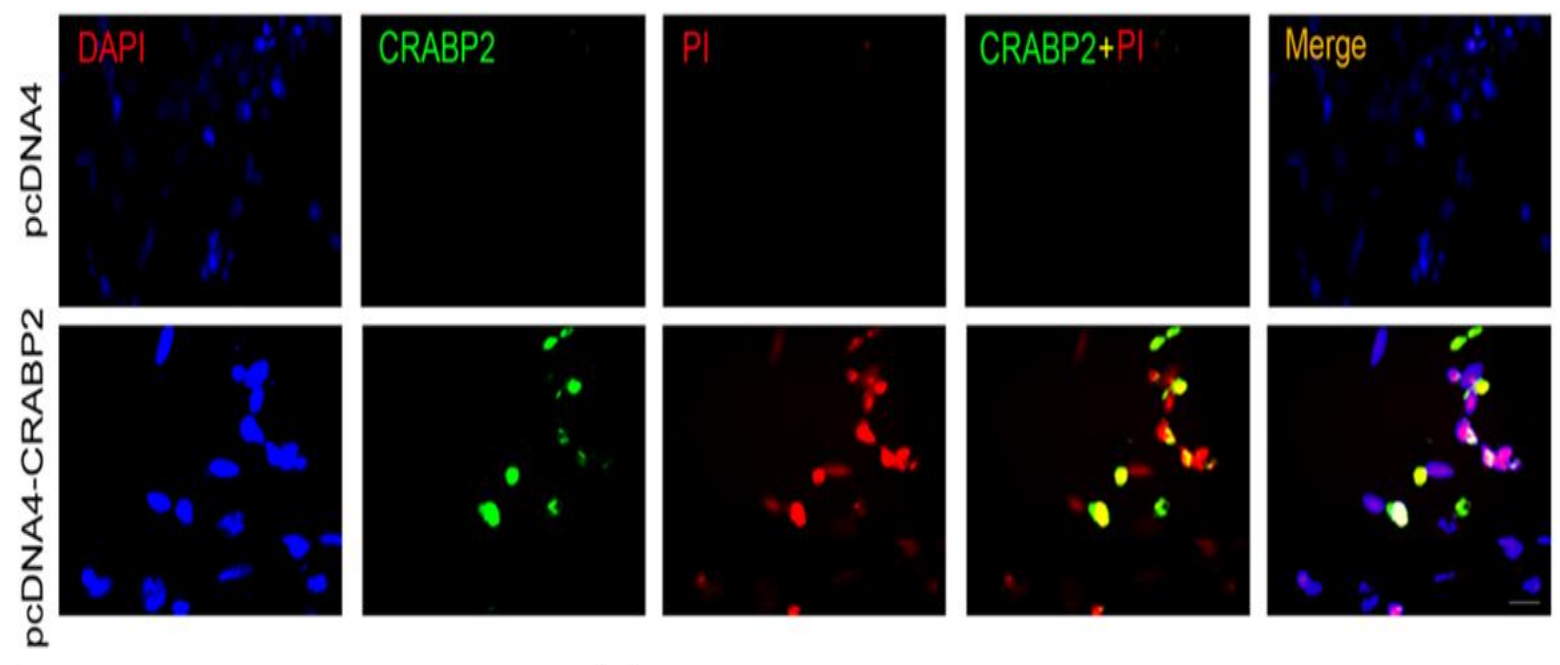

Figure 17. Overexpression of CRABP2 as well as VPA treatment increase apoptosis in vitro. Transfection of U87MG glioblastoma cells with pcDNA4-CRABP2 plasmid increased cell death as detected by staining with the fluorescent molecule, propidium iodide (PI). The scale bar is $50 \mu \mathrm{m}$.

Real-time PCR also showed that U87MG and 36st cells over-expressing CRABP2 by transfection of pcDNA4-CRABP2 plasmid (Figure 18) distinctly induced more Caspase 7 in comparison to the control transfected with plasmid without CRABP2 coding sequence $(p=0.0333, p=0.0447$; Figure 19).

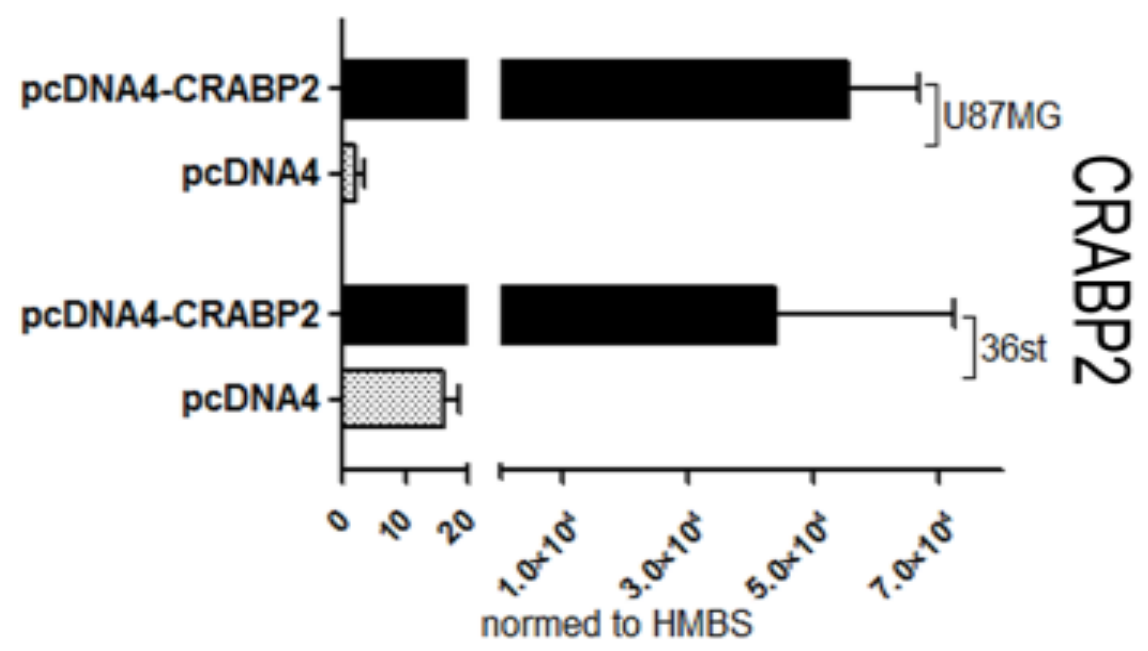

Figure 18. CRABP2 expression level in U87MG (up) and 36st cells (down) after transfection of pcDNA4-CRABP2 plasmid. 


\section{U87MG Caspase7}

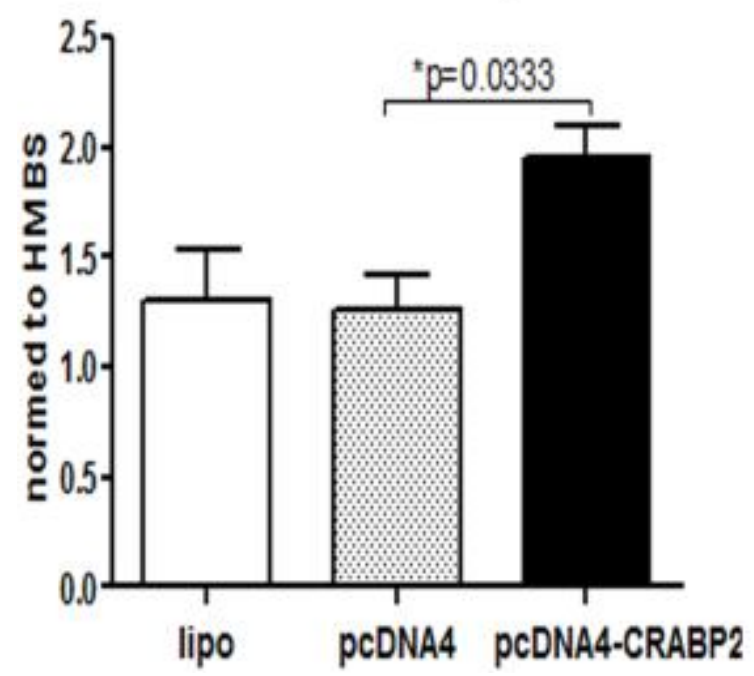

36st Caspase7

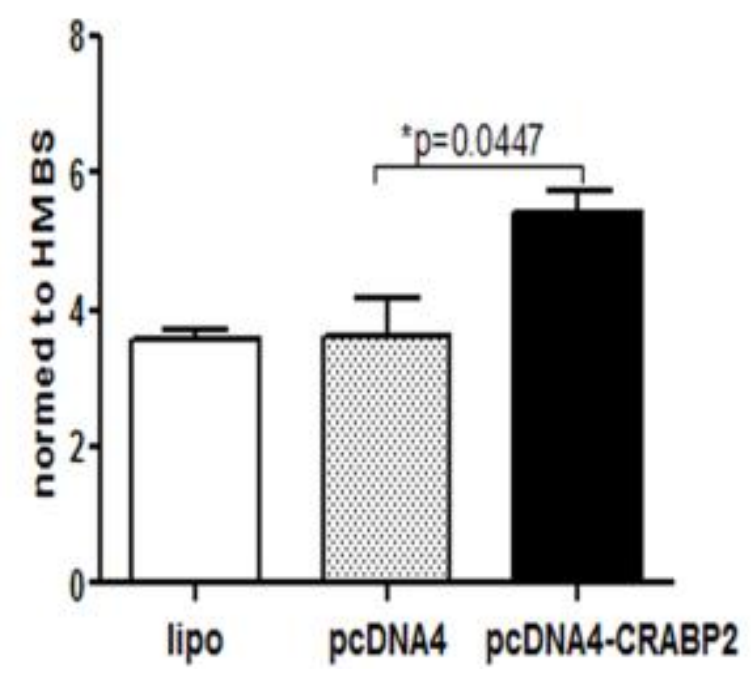

Figure 19. Caspase $7 \mathrm{mRNA}$ level in U87MG (left) and 36st (right) cells with over-expressing CRABP2. Bars depict mean \pm S.E.M. from three independent experiments. Statistical analysis was performed using two-sided t-tests for two-group comparisons ( $\left.{ }^{*} \mathrm{P}<0.05\right)$.

Furthermore, GBM cells over-expressing CRABP2 showed Caspase 7 mRNA increase which correlates with the increased Caspase 7 after $V+R$ treatment $(p=0.0457)$ (Figure 20). Interestingly, although of similar tendency, significant increase in Caspase 7 has not been observed for the 36st cell line treated with VPA or $V_{+} R$. It is possible that a different genetic background, for example influence of intact HuR protein plays a role in this cell line. 
U87MG Caspase7

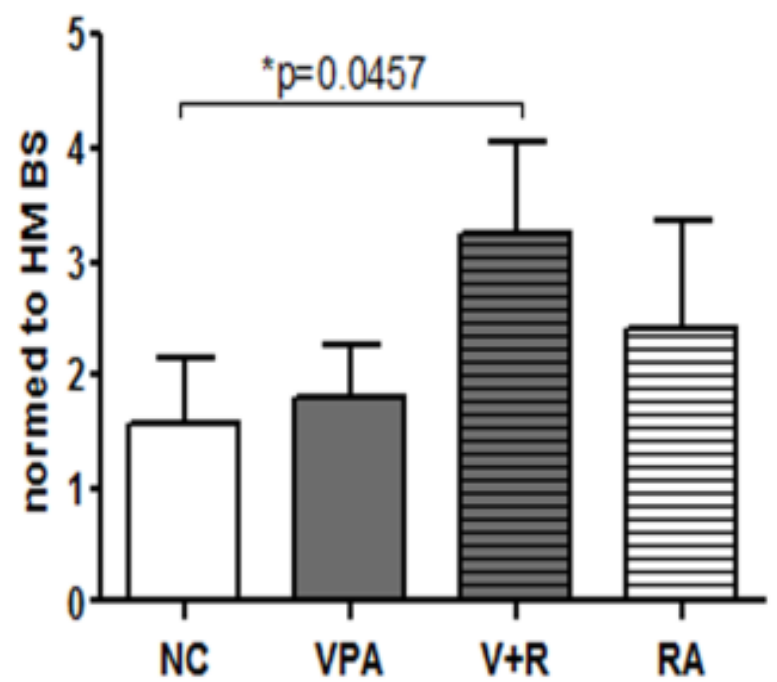

36st Caspase7

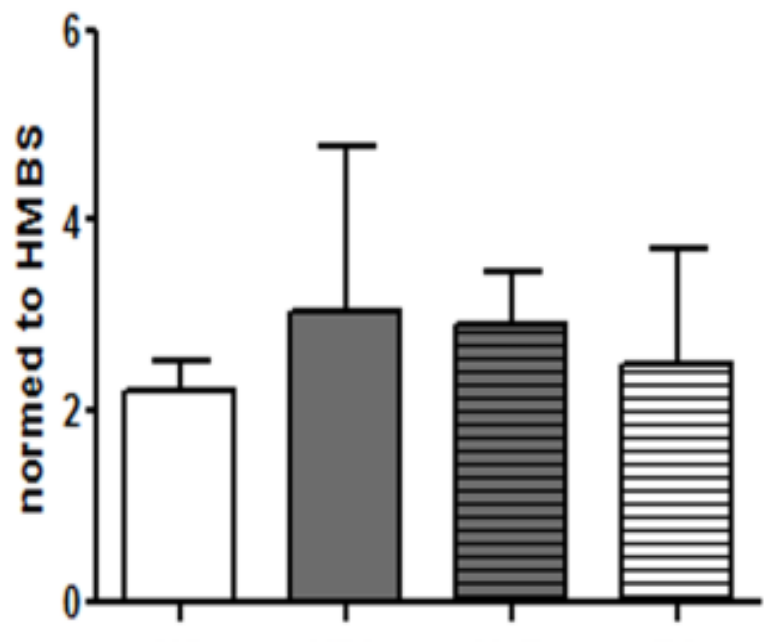

NC

Figure 20. In correlation with GBM cells over-expressing CRABP2, VPA-treated groups showed increased Caspase 7 mRNA expression. Considerable increase was detected in U87MG cells after $\mathrm{V}+\mathrm{R}$ treatment (left, $\mathrm{p}=0.0457$ ). Bars depict mean \pm S.E.M. from three independent experiments. Statistical analysis was performed using two-sided t-tests for twogroup comparisons $\left({ }^{*} \mathrm{P}<0.05\right)$.

Considering the fact that GBM are characterized by high expression level of antiapoptotic Bcl-2 protein (Krajewski et al. 1997, Kraus et al. 2001) we examined the influence of $\mathrm{V}+\mathrm{R}$ on its mRNA expression level. Both tested cell lines displayed remarkably lower mRNA expression of anti-apoptotic member Bcl-2, especially in $\mathrm{V}+\mathrm{R}$ group $(\mathrm{p}=0.0139, \mathrm{p}=0.0466$, Figure 21). 

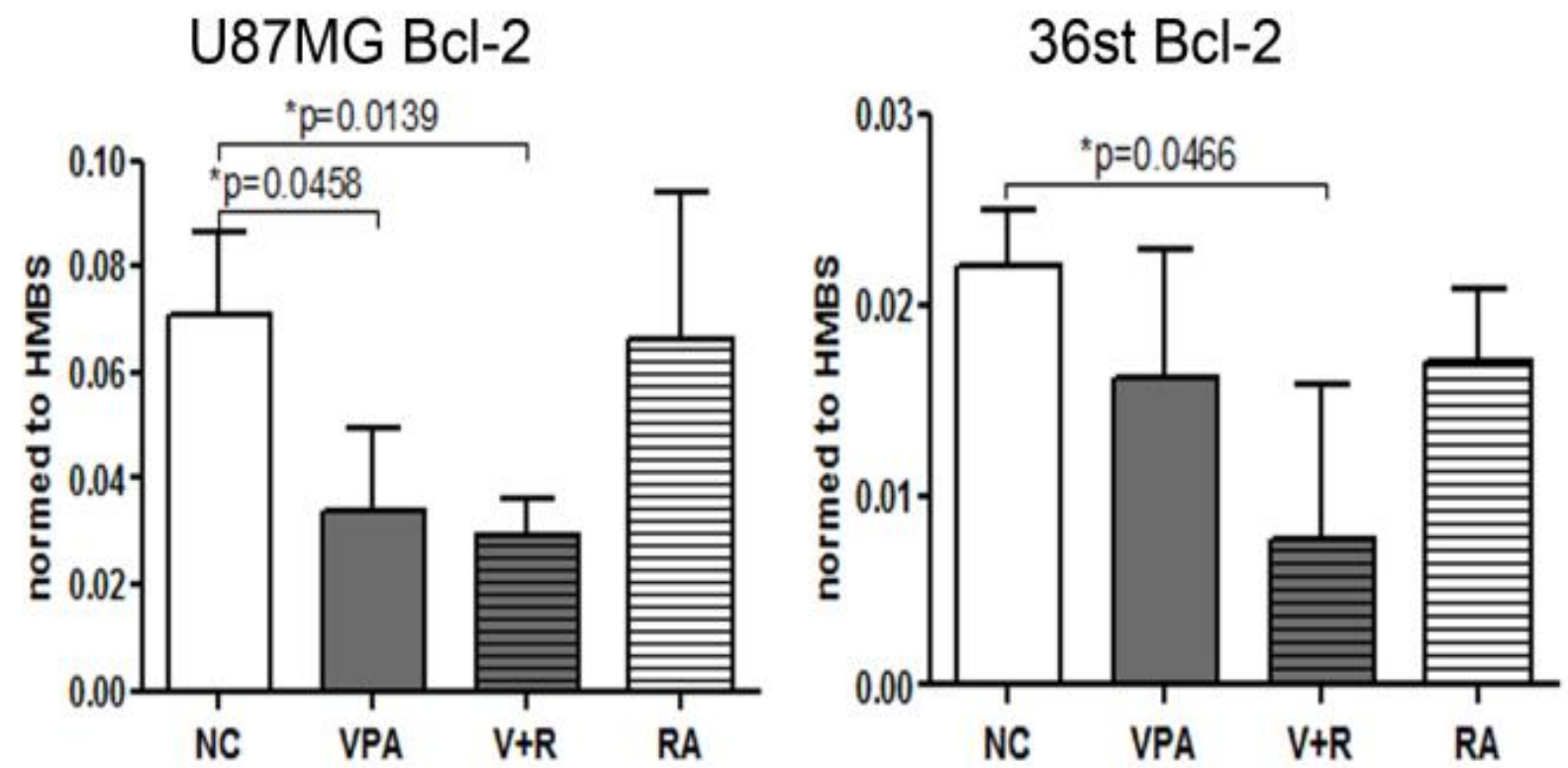

Figure 21. mRNA expression of anti-apoptotic marker Bcl-2 in U87MG (left) and 36st (right) cells. Lower expression of $\mathrm{Bcl}-2$ was detected especially in $\mathrm{V}+\mathrm{R}$ group $(\mathrm{p}=0.0139, \mathrm{p}=0.0466)$. Bars depict mean \pm S.E.M. from three independent experiments. Statistical analysis was performed using two-sided t-tests for two-group comparisons ( $\left.{ }^{*} \mathrm{P}<0.05\right)$. 


\section{DISSCUSION}

Alterations in RA signaling are very frequently observed in GBM (Campos et al. 2011) and are used to explain RA resistance in some cases (Campos et al. 2015, Zhou et al. 2015). Recently, Yang et al. (2016) showed downregulation of CRABP2 in human esophageal squamous cell carcinoma and its role as a tumor suppressor (Yang et al. 2016). Among CNS proteins CRABP2 plays a crucial role in RA pathway and is downregulated in medulloblastoma and GBM. The downregulation is at least partially due to the aberrant methylation in its promoter (Fu et al. 2012, Campos et al. 2012).

\subsection{Decrease of CRABP2 in GBM is not modulated by hsa-mir-34a and hsa-mir- 1262 and mutation in K102}

It is already known that upregulation or downregulation of miRNAs alter the expression of a lot of proteins in GBM (Tao et al. 2013, Que et al. 2015, Hu et al. 2016). My assumption that miRNAs: hsa-mir-34a and hsa-mir-1262 can target CRABP2 mRNA 3'UTR and potentially be responsible for downregulation of CRABP2 in GBM could not be confirmed. In fact, according to miRNA database, besides hsamir-34a and hsa-mir-1262, there are still numerous predicted potential miRNAs which are supposed to target CRABP2 but which are not tested in this study. Furthermore, hsa-mir-34a and hsa-mir-1262 have also other target genes which may have indirect effect on RA pathway in GBM. Based on these views, I still could not exclude miRNAs as one of the reasons leading to downregulation of CRABP2.

Majumdar et al. (2011) demonstrated that K102 in CRABP2 is the residue which is SUMOylated, and SUMOylation of CRABP2 could enhance its translocation to the nucleus in response to RA (Majumdar et al. 2011). Since in GBM CRABP2 is mostly located in cytoplasm I assumed the mutation in this amino acid could be responsible for CRABP2 cytoplasmic localization (Liu et al. 2016). However, I could not detect any mutation in $\mathrm{K} 102$ residue of CRABP2, in analyzed GBM samples. But nevertheless 
the aberrant SUMOylation in GBM could not be completely excluded since this study did not directly address the Ubc 9 or other key SUMOylational enzymes analysis (Hsieh et al. 2013).

\subsection{CRABP2 expression increases after VPA treatment in GBM cells}

Data presented in this work shows that the HDAC inhibitor VPA increases expression of CRABP2 in two GBM cell lines. That increase could be due to the known function of VPA as an HDAC inhibitor, leading to decondensation of the chromatin which in turn derives to subsequent higher expression of CRABP2. Alternatively this effect could be the consequence of the VPA effect on downregulation of DNMT1 (Sarkar et al. 2011) enzyme activity on the promotor region of CRABP2 gene (Figure 15). DNMT1 adds methyl groups on the fifth carbon of cytosine at $\mathrm{CpG}$ sites and therefore results in DNA methylation that finally leads to suppression of gene transcription. Hence, inhibition or inactivation of DNMT1 leads to DNA hypomethylation or demethylation, in this case possibly of the CRABP2 promotor region (Brodie et al. 2014). On the other hand, VPA has been discovered to induce DNA hypomethylation in rat astrocytes and that is reversible and independent of DNMT1 (Perisic et al. 2010). In this case these results would suggest that VPA affects chromatin remodeling properties of active demethylation machinery in the promoter regions of DNMT1 and CRABP2. Direct influence of DNMT1 on CRABP2 promotor methylation was not examined in this study.

\subsection{Nuclear re-localization of CRABP2 after VPA+RA in GBM cells}

ICC staining confirmed the expression of CRABP2 protein, as well as indicating its cytoplasmic localization after exposure to VPA. Further increase of CRABP2 protein expression, as well as more nuclear localization, was observed when VPA was added to the GBM cell lines in combination with RA (Figure 8 B and D). This is in agreement with the known, and main, function of CRABP2 protein, to transport RA to the nucleus (Connolly et al. 2013) and that transcription of CRABP2 is RA dependent (Astrom et al. 1994). Moreover VPA and RA application lowers the ratio of FABP5/CRABP2 protein. This ratio has been described to be an important difference 
between long and short term GBM survivors (Barbus et al. 2011). LTS GBM patients have lower FABP5/CRABP2 ratio compared to STS which show higher FABP5/CRABP2 ratio (Barbus et al. 2011).

\subsection{VPA+RA treatment increased apoptosis and decreased proliferation in GBM cells}

VPA treatment increased apoptosis in both GBM cell lines. Yet again a stronger effect on the cell death of these cell lines was increased under combined treatment. It is already known that VPA induces apoptosis in GBM by influencing the balance between pro-apoptotic genes such as Bax, p53 and anti-apoptotic genes such as Chk1 and Bcl-2 (Cornago et al. 2014). Similar VPA effects on gene expression have also been described in cervical carcinoma (Feng et al. 2012). Treatment of GBM cell lines with VPA confirmed the known effect on downregulation of the anti-apoptotic gene Bcl-2. Combining $\mathrm{V}+\mathrm{R}$, increased the expression of Caspase 7 , an apoptotic marker. This increase is at least partially due to the expression of CRABP2, because transfection of CRABP2 into these GBM cell lines led to a similar increase of Caspase 7 mRNA. This result is in agreement with another recently shown function of CRABP2, in stabilizing some mRNA through interaction with HuR (Vreeland et al. 2014b). Vreeland et al. (2014a) have presented a mechanism which explains anticarcinogenetic activity of CRABP2 with or without RA in GBM (Vreeland et al. 2014a). It includes involvement of CRABP2 in HuR-mediated mRNA stabilization, in addition to the RAR mediated transcriptional regulation.

Based on above presented results, I speculate that, on one side CRABP2 directly interacts with HuR, markedly improving its RNA-binding affinity, and therefore boosting the stability of HuR-targeted transcripts, for example Caspase 7 mRNA (Figure 22). On the other hand, binding of CRABP2 to RA induces its dissociation from HuR. Once bound to RA it is transported to the nucleus, where it delivers RA to RAR, enhancing the transcriptional activity (Figure 22). 
These would be in agreement with Vreeland et al. (2014b) who demonstrated the anti-carcinogenic activity of CRABP2 is by promoting HuR-mediated stabilization of transcripts of proteins that inhibit proliferation, and by raising RA-induced RARmediated transcription of growth-inhibitory genes (Vreeland et al. 2014b). Results of this study have shown that VPA increases CRABP2 cytoplasmic expression which in turn induces apoptosis, e.g. through stabilization of Caspase 7 mRNA. The addition of RA causes translocation of CRABP2 to the nucleus which further induces apoptosis due to the activation of RAR genes.

Additionally, it is important to mention that transcription of CRABP2 is RA-dependent so that RA not only activates RAR genes but is also responsible for its own transcription and own turnover (Astrom et al. 1994). Increased cell death and decreased proliferation by combined treatment is at least partially a consequence of these effects, since I cannot exclude the influence of VPA on overall gene expression and its changes in distinct biological pathways (Zhang et al. 2013).

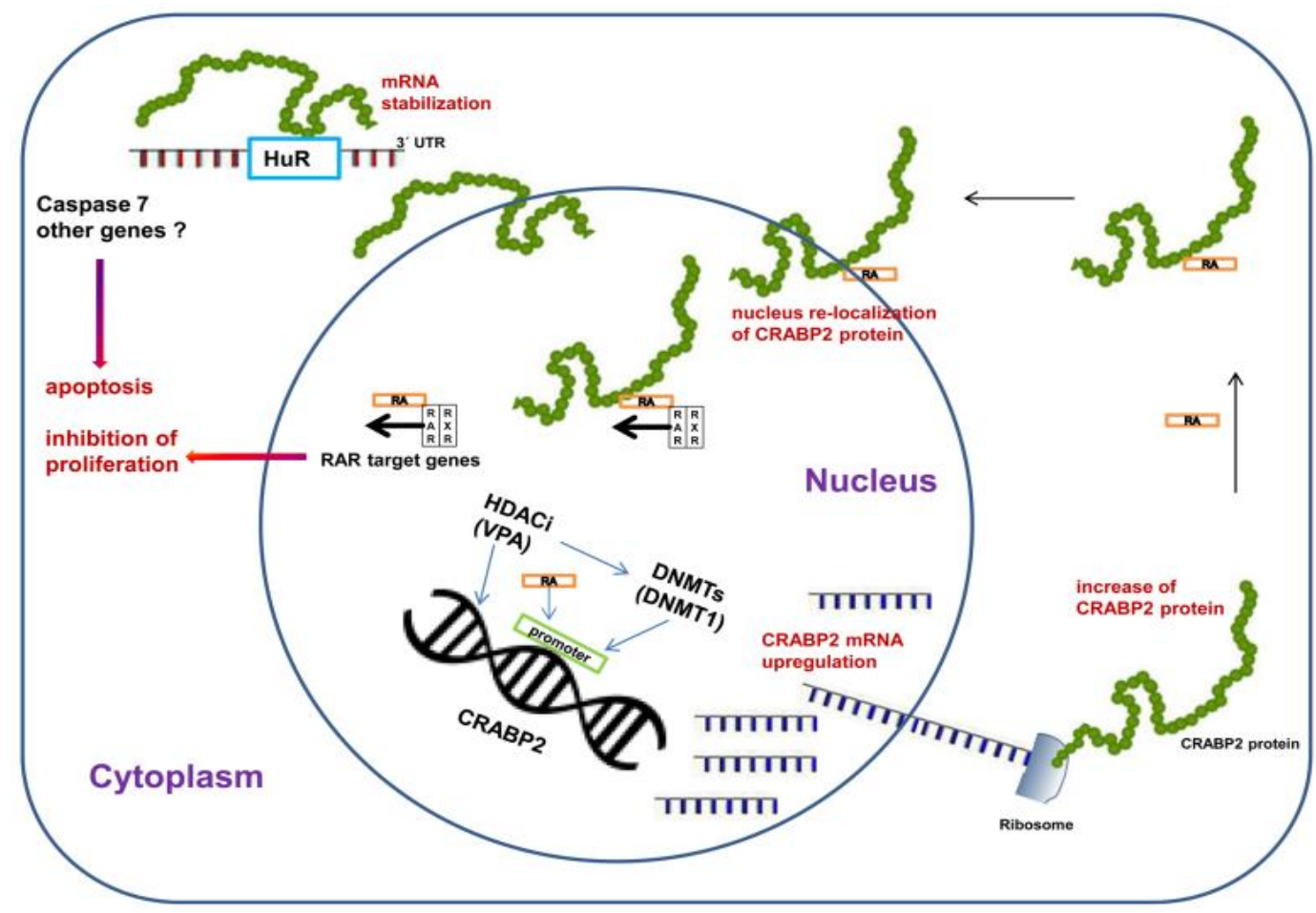

Figure 22. Hypothetical schematic representation (modified from Vreeland et al. (2014a)) of 
potential action of VPA+RA on CRABP2 expression in U87MG and 36st glioblastoma cell lines. VPA induces expression of CRABP2 in cytoplasm which can bind HuR protein and enhances the stability of Caspase 7 mRNA and induces apoptosis in these cells. Added RA binds to CRABP2 protein in cytoplasm and is delivered to the nucleus where it induces RARmediated transcriptional regulation which leads to the inhibition of proliferation. Additionally, CRABP2 is RA-dependent so that RA not only activates RAR genes but is also responsible for its own transcription and own turnover.

\subsection{Potential of VPA+RA as anti-cancer therapy in GBM}

In human breast cancer cells Mongan and Gudas (2005) revealed that VPA, in combination with RA and the DNA methyltransferase inhibitor 5-aza, can overcome the epigenetic barriers to transcription of a prototypical silenced tumor suppressor gene, RARß2 (Mongan and Gudas 2005). VPA is an approved classic drug for the treatment of epileptic seizures, bipolar disorders, and migraine (Mongan and Gudas 2005). Recently VPA is being conducted in different countries in Phase 1 and 2 clinical trials as an anti-cancer drug for the treatment of GBM, alone or in combination with TMZ or radiation (Clinicaltrials.gov ID: NCT00943826, NCT00689221, NCT00313664). RA with its anti-carcinogenic properties was tested for therapy in several types of human cancer including GBM (Yung et al. 1996). The data from cell viability assay with $2 \mathrm{mM}$ and $5 \mathrm{mM}$ VPA in combination with RA also suggests the possibility to reduce the dose of VPA in order to reduce the side effect of VPA. The combination of VPA with RA has not been conducted in anti-cancer therapy in GBM patients. Even though the results I presented here need more support with in vivo experiments, it could encourage evaluation of this drug combination in anti-glioma therapy and particularly in the improvement of survival time of the STS GBM patients. 


\section{CONCLUSIONS}

In this study, I examined various possibilities which could be responsible for downregulation of CRABP2 in GBM, including epigenetic causes such as miRNAs, DNA methylation and histone deacetylation. Sequence analysis of residue K102, in GBM tissue and cell lines, responsible for posttranslational modification, was also performed.

My data showed that CRABP2 is not the target of miRNA-34a and miRNA-1262. There is no mutation in K102 of CRABP2 amino acid responsible for the interaction with Ubc9, SUMO ligase which triggers the SUMOylation. However, I could confirm that DNA methylation inhibitor 5-aza can increase CRABP2 expression and inhibits cell viability in GBM cell lines. Moreover, I investigated the anti-cancer mechanism of VPA alone and in combination with RA testing their influence on the CRABP2 protein, in vitro. Here I revealed at first that VPA increases expression of CRABP2 in cytoplasm of GBM cell lines contributing to the clinical properties of VPA in GBM. The combination of VPA with RA increases CRABP2 expression further. Inhibition of proliferation and increase in apoptosis in GBM cells are probably due to the two distinct mechanisms. In conclusion this data supports the statement that VPA as HDAC inhibitor has anti-cancer properties in GBM and further suggests that VPA in combination with RA can be a promising anti-cancer therapy for GBM and could improve the survival time of STS GBM patients. 


\section{REFERENCES}

Adamson C, Kanu OO, Mehta AI, Di C, Lin N, Mattox AK, Bigner DD (2009): Glioblastoma multiforme: a review of where we have been and where we are going. Expert Opin Investig Drugs 18, 1061-1083

Altucci L, Gronemeyer H (2001): The promise of retinoids to fight against cancer. Nat Rev Cancer 1, 181-193

Arrieta O, Hernandez-Pedro N, Fernandez-Gonzalez-Aragon MC, Saavedra-Perez D, Campos-Parra AD, Rios-Trejo MA, Ceron-Lizarraga T, Martinez-Barrera L, Pineda B, Ordonez G, Ortiz-Plata A, Granados-Soto V, Sotelo J (2011): Retinoic acid reduces chemotherapy-induced neuropathy in an animal model and patients with lung cancer. Neurology $\underline{77}, 987-995$

Astrom A, Pettersson U, Chambon P, Voorhees JJ (1994): Retinoic acid induction of human cellular retinoic acid-binding protein-II gene transcription is mediated by retinoic acid receptor-retinoid $X$ receptor heterodimers bound to one far upstream retinoic acidresponsive element with 5-base pair spacing. J Biol Chem $\underline{269}$, 22334-22339

Barbus S, Tews B, Karra D, Hahn M, Radlwimmer B, Delhomme N, Hartmann C, Felsberg J, Krex D, Schackert G, Martinez R, Reifenberger G, Lichter P (2011): Differential retinoic acid signaling in tumors of long- and short-term glioblastoma survivors. J Natl Cancer Inst $\underline{103}, 598-606$

Brodie SA, Li G, El-Kommos A, Kang H, Ramalingam SS, Behera M, Gandhi K, Kowalski J, Sica GL, Khuri FR, Vertino PM, Brandes JC (2014): Class I HDACs are mediators of smoke carcinogen-induced stabilization of DNMT1 and serve as promising targets for chemoprevention of lung cancer. Cancer Prev Res $\underline{7}, 351-361$

Bryan M, Pulte ED, Toomey KC, Pliner L, Pavlick AC, Saunders T, Wieder R (2011): A pilot phase II trial of all-trans retinoic acid (Vesanoid) and paclitaxel (Taxol) in patients with recurrent or metastatic breast cancer. Invest New Drugs 29, 1482-1487

Buntzel J, Kuttner K (1998): Chemoprevention with interferon alfa and 13-cis retinoic acid in the adjunctive treatment of head and neck cancer. Auris Nasus Larynx $\underline{25}$, 413-418

Campos B, Centner FS, Bermejo JL, Ali R, Dorsch K, Wan F, Felsberg J, Ahmadi R, Grabe N, Reifenberger G, Unterberg A, Burhenne J, Herold-Mende C (2011): Aberrant expression of retinoic acid signaling molecules influences patient survival in astrocytic gliomas. Am J Pathol $\underline{178}, 1953-1964$ 
Campos B, Warta R, Chaisaingmongkol J, Geiselhart L, Popanda O, Hartmann C, von Deimling A, Unterberg A, Plass C, Schmezer P, Herold-Mende C (2012): Epigenetically mediated downregulation of the differentiation-promoting chaperon protein CRABP2 in astrocytic gliomas. Int J Cancer 131, 1963-1968

Campos B, Weisang S, Osswald F, Ali R, Sedlmeier G, Bageritz J, Mallm JP, Hartmann C, von Deimling A, Popanda O, Goidts V, Plass C, Unterberg A, Schmezer P, Burhenne J, Herold-Mende C (2015): Retinoid resistance and multifaceted impairment of retinoic acid synthesis in glioblastoma. Glia $\underline{63}, 1850-1859$

Chambon P (1996): A decade of molecular biology of retinoic acid receptors. FASEB J 10, 940-954

Chen PH, Shih CM, Chang WC, Cheng CH, Lin CW, Ho KH, Su PC, Chen KC (2014): MicroRNA-302b-inhibited E2F3 transcription factor is related to all trans retinoic acidinduced glioma cell apoptosis. J Neurochem 131, 731-742

Chen X, Wong P, Radany E, Wong JY (2009): HDAC inhibitor, valproic acid, induces p53dependent radiosensitization of colon cancer cells. Cancer Biother Radiopharm $\underline{24}$, 689-699

Chomienne C, Ballerini P, Balitrand N, Daniel MT, Fenaux P, Castaigne S, Degos L (1990): All-trans retinoic acid in acute promyelocytic leukemias. II. In vitro studies: structurefunction relationship. Blood $\underline{76}, 1710-1717$

Chou TC, Talalay P (1984): Quantitative analysis of dose-effect relationships: the combined effects of multiple drugs or enzyme inhibitors. Adv Enzyme Regul 22, 27-55

Codrici E, Enciu AM, Popescu ID, Mihai S, Tanase C (2016): Glioma Stem Cells and Their Microenvironments: Providers of Challenging Therapeutic Targets. Stem Cells Int $\underline{2016}, 5728438$

Connolly RM, Nguyen NK, Sukumar S (2013): Molecular pathways: current role and future directions of the retinoic acid pathway in cancer prevention and treatment. Clin Cancer Res $\underline{19}, 1651-1659$

Corlazzoli F, Rossetti S, Bistulfi G, Ren M, Sacchi N (2009): Derangement of a factor upstream of RARalpha triggers the repression of a pleiotropic epigenetic network. PLoS One $\underline{4}$, e4305

Cornago M, Garcia-Alberich C, Blasco-Angulo N, Vall-Llaura N, Nager M, Herreros J, Comella JX, Sanchis D, Llovera M (2014): Histone deacetylase inhibitors promote glioma cell death by G2 checkpoint abrogation leading to mitotic catastrophe. Cell Death Dis $\underline{5}$, e1435

Degos L, Wang ZY (2001): All trans retinoic acid in acute promyelocytic leukemia. Oncogene $\underline{20}, 7140-7145$ 
Donato LJ, Noy N (2005): Suppression of mammary carcinoma growth by retinoic acid: proapoptotic genes are targets for retinoic acid receptor and cellular retinoic acidbinding protein II signaling. Cancer Res $\underline{65}, 8193-8199$

Donato LJ, Suh JH, Noy N (2007): Suppression of mammary carcinoma cell growth by retinoic acid: the cell cycle control gene Btg2 is a direct target for retinoic acid receptor signaling. Cancer Res $\underline{67}, 609-615$

Feng D, Cao Z, Li C, Zhang L, Zhou Y, Ma J, Liu R, Zhou H, Zhao W, Wei H, Ling B (2012): Combination of valproic acid and ATRA restores RARbeta2 expression and induces differentiation in cervical cancer through the PI3K/Akt pathway. Curr Mol Med $\underline{12}$, 342-354

Foley NH, Bray I, Watters KM, Das S, Bryan K, Bernas T, Prehn JH, Stallings RL (2011): MicroRNAs $10 \mathrm{a}$ and $10 \mathrm{~b}$ are potent inducers of neuroblastoma cell differentiation through targeting of nuclear receptor corepressor 2. Cell Death Differ 18, 1089-1098

Fu YS, Wang Q, Ma JX, Yang XH, Wu ML, Zhang KL, Kong QY, Chen XY, Sun Y, Chen NN, Shu XH, Li H, Liu J (2012): CRABP-II methylation: a critical determinant of retinoic acid resistance of medulloblastoma cells. Mol Oncol $\underline{6}, 48-61$

Garg AD, Vandenberk L, Koks C, Verschuere T, Boon L, Van Gool SW, Agostinis P (2016): Dendritic cell vaccines based on immunogenic cell death elicit danger signals and $T$ cell-driven rejection of high-grade glioma. Sci Transl Med $\underline{8}, 328$ ra327

He L, Hannon GJ (2004): MicroRNAs: small RNAs with a big role in gene regulation. Nat Rev Genet $\underline{5}, 522-531$

Hosein AN, Lim YC, Day B, Stringer B, Rose S, Head R, Cosgrove L, Sminia P, Fay M, Martin JH (2015): The effect of valproic acid in combination with irradiation and temozolomide on primary human glioblastoma cells. J Neurooncol $\underline{122}, 263-271$

Hsieh YL, Kuo HY, Chang CC, Naik MT, Liao PH, Ho CC, Huang TC, Jeng JC, Hsu PH, Tsai MD, Huang TH, Shih HM (2013): Ubc9 acetylation modulates distinct SUMO target modification and hypoxia response. EMBO $\mathrm{J} \underline{32}, 791-804$

Hu HQ, Sun LG, Guo WJ (2016): Decreased miRNA-146a in glioblastoma multiforme and regulation of cell proliferation and apoptosis by target Notch1. Int $\mathrm{J}$ Biol Markers, epub

Jing Y, Waxman S, Mira-y-Lopez R (1997): The cellular retinoic acid binding protein II is a positive regulator of retinoic acid signaling in breast cancer cells. Cancer Res $\underline{57}$, 1668-1672

Kaba SE, Kyritsis AP, Conrad C, Gleason MJ, Newman R, Levin VA, Yung WK (1997): The treatment of recurrent cerebral gliomas with all-trans-retinoic acid (tretinoin). $J$ Neurooncol $\underline{34}, 145-151$ 
Kim TY, Zhong S, Fields CR, Kim JH, Robertson KD (2006): Epigenomic profiling reveals novel and frequent targets of aberrant DNA methylation-mediated silencing in malignant glioma. Cancer Res $\underline{66}, 7490-7501$

Krajewski S, Krajewska M, Ehrmann J, Sikorska M, Lach B, Chatten J, Reed JC (1997): Immunohistochemical analysis of $\mathrm{Bcl}-2, \mathrm{Bcl}-\mathrm{X}, \mathrm{Mcl}-1$, and $\mathrm{Bax}$ in tumors of central and peripheral nervous system origin. Am J Pathol 150, 805-814

Kraus JA, Wenghoefer M, Glesmann N, Mohr S, Beck M, Schmidt MC, Schroder R, Berweiler U, Roggendorf W, Diete S, Dietzmann K, Heuser K, Muller B, Fimmers R, von Deimling A, Schlegel U (2001): TP53 gene mutations, nuclear p53 accumulation, expression of Waf/p21, Bcl-2, and CD95 (APO-1/Fas) proteins are not prognostic factors in de novo glioblastoma multiforme. J Neurooncol $\underline{52}, 263-272$

Leitch C, Osdal T, Andresen V, Molland M, Kristiansen S, Nguyen XN, Bruserud O, Gjertsen BT, McCormack E (2016): Hydroxyurea synergizes with valproic acid in wild-type p53 acute myeloid leukaemia. Oncotarget $\underline{7}, 8105-8118$

Liu RZ, Graham K, Glubrecht DD, Germain DR, Mackey JR, Godbout R (2011): Association of FABP5 expression with poor survival in triple-negative breast cancer: implication for retinoic acid therapy. Am J Pathol 178, 997-1008

Liu RZ, Li S, Garcia E, Glubrecht DD, Yin Poon H, Easaw JC, Godbout R (2016): Association between cytoplasmic CRABP2, altered retinoic acid signaling, and poor prognosis in glioblastoma. Glia, epub

Louis DN, Ohgaki H, Wiestler OD, Cavenee WK, Burger PC, Jouvet A, Scheithauer BW, Kleihues $P$ (2007): The 2007 WHO classification of tumours of the central nervous system. Acta Neuropathol 114, 97-109

Majumdar A, Petrescu AD, Xiong Y, Noy N (2011): Nuclear translocation of cellular retinoic acid-binding protein II is regulated by retinoic acid-controlled SUMOylation. J Biol Chem 286, 42749-42757

Mangelsdorf DJ (1994): Vitamin A receptors. Nutr Rev $\underline{52}$, S32-44

Mongan NP, Gudas LJ (2005): Valproic acid, in combination with all-trans retinoic acid and 5aza-2 '-deoxycytidine, restores expression of silenced RAR beta 2 in breast cancer cells. Molecular Cancer Therapeutics $\underline{4}, 477-486$

Muller S, Hoege C, Pyrowolakis G, Jentsch S (2001): SUMO, ubiquitin's mysterious cousin. Nature reviews Molecular cell biology 2, 202-210

Nagarajan RP, Costello JF (2009): Epigenetic mechanisms in glioblastoma multiforme. Semin Cancer Biol 19, 188-197

Niles RM (2002): The use of retinoids in the prevention and treatment of skin cancer. Expert Opin Pharmacother $\underline{3}, 299-303$ 
Ohgaki H, Kleihues P (2005): Population-based studies on incidence, survival rates, and genetic alterations in astrocytic and oligodendroglial gliomas. J Neuropathol Exp Neurol 64 , 479-489

Perisic T, Zimmermann N, Kirmeier T, Asmus M, Tuorto F, Uhr M, Holsboer F, Rein T, Zschocke J (2010): Valproate and amitriptyline exert common and divergent influences on global and gene promoter-specific chromatin modifications in rat primary astrocytes. Neuropsychopharmacology $\underline{35}, 792-805$

Phuphanich S, Scott C, Fischbach AJ, Langer C, Yung WK (1997): All-trans-retinoic acid: a phase II Radiation Therapy Oncology Group study (RTOG 91-13) in patients with recurrent malignant astrocytoma. J Neurooncol $\underline{34}$, 193-200

Que T, Song Y, Liu Z, Zheng S, Long H, Li Z, Liu Y, Wang G, Liu Y, Zhou J, Zhang X, Fang W, Qi S (2015): Decreased miRNA-637 is an unfavorable prognosis marker and promotes glioma cell growth, migration and invasion via direct targeting Akt1. Oncogene 34, 4952-4963

Rajendran G, Shanmuganandam K, Bendre A, Muzumdar D, Goel A, Shiras A (2011): Epigenetic regulation of DNA methyltransferases: DNMT1 and DNMT3B in gliomas. $J$ Neurooncol 104, 483-494

Rochette-Egly C, Chambon P (2001): F9 embryocarcinoma cells: a cell autonomous model to study the functional selectivity of RARs and RXRs in retinoid signaling. Histol Histopathol 16, 909-922

Sarkar S, Abujamra AL, Loew JE, Forman LW, Perrine SP, Faller DV (2011): Histone deacetylase inhibitors reverse $\mathrm{CpG}$ methylation by regulating DNMT1 through ERK signaling. Anticancer Res 31, 2723-2732

Schug TT, Berry DC, Shaw NS, Travis SN, Noy N (2007): Opposing effects of retinoic acid on cell growth result from alternate activation of two different nuclear receptors. Cell $\underline{129}, 723-733$

Scott A, Song J, Ewing R, Wang Z (2014): Regulation of protein stability of DNA methyltransferase 1 by post-translational modifications. Acta Biochim Biophys Sin $\underline{46}$, 199-203

Shirai K, Chakravarti A (2011): Towards personalized therapy for patients with glioblastoma. Expert Rev Anticancer Ther 11, 1935-1944

Tao T, Wang Y, Luo H, Yao L, Wang L, Wang J, Yan W, Zhang J, Wang H, Shi Y, Yin Y, Jiang T, Kang C, Liu N, You Y (2013): Involvement of FOS-mediated miR-181b/miR21 signalling in the progression of malignant gliomas. Eur J Cancer $\underline{49}, 3055-3063$

Terranova-Barberio M, Roca MS, Zotti Al, Leone A, Bruzzese F, Vitagliano C, Scogliamiglio G, Russo D, D'Angelo G, Franco R, Budillon A, Di Gennaro E (2016): Valproic acid 
potentiates the anticancer activity of capecitabine in vitro and in vivo in breast cancer models via induction of thymidine phosphorylase expression. Oncotarget $\underline{7}, 7715$ 7731

Vreeland AC, Levi L, Zhang W, Berry DC, Noy N (2014a): Cellular retinoic acid-binding protein 2 inhibits tumor growth by two distinct mechanisms. J Biol Chem $\underline{289}$, 3406534073

Vreeland AC, Yu S, Levi L, de Barros Rossetto D, Noy N (2014b): Transcript stabilization by the RNA-binding protein HuR is regulated by cellular retinoic acid-binding protein 2 . Mol Cell Biol 34, 2135-2146

Wang Y, Xing D, Zhao M, Wang J, Yang Y (2016): The Role of a Single Angiogenesis Inhibitor in the Treatment of Recurrent Glioblastoma Multiforme: A Meta-Analysis and Systematic Review. PLoS One 11, e0152170

Wen PY, Kesari S (2008): Malignant gliomas in adults. N Engl J Med $\underline{359}, 492-507$

Yang Q, Wang R, Xiao W, Sun F, Yuan H, Pan Q (2016): Cellular Retinoic Acid Binding Protein 2 Is Strikingly Downregulated in Human Esophageal Squamous Cell Carcinoma and Functions as a Tumor Suppressor. PLoS One 11, e0148381

Yung WK, Kyritsis AP, Gleason MJ, Levin VA (1996): Treatment of recurrent malignant gliomas with high-dose 13-cis-retinoic acid. Clin Cancer Res $\underline{2}, 1931-1935$

Zhang Z, Convertini P, Shen M, Xu X, Lemoine F, de la Grange P, Andres DA, Stamm S (2013): Valproic acid causes proteasomal degradation of DICER and influences miRNA expression. PLoS One $\underline{8}$, e82895

Zhou N, Yao Y, Ye H, Zhu W, Chen L, Mao Y (2015): Abscisic acid-induced cellular apoptosis and differentiation in glioma via the retinoid acid signaling pathway. Int $\mathrm{J}$ Cancer 138, 1947-1958 


\section{ACKNOWLEDGEMENTS}

Firstly, I really thank my supervisor Prof. Dr. med Veit Rohde for his continuously full support of my doctorate study, and for his valuable guidance, positive criticism and extreme patience with my work. Also thanks for giving me the chance to further continue my pursuit in medicine in Germany.

Besides my supervisor, I do thank my lab leader Dr. Milena Ninkovic. Thousands of thanks for her patience, motivation, generosity and immense knowledge. Her guidance has helped me during all the time of research and throughout the completion of this dissertation. I could not have imagined having a better lab leader and mentor for my doctorate study. My sincere thanks also go to lab technician Miss Swetlana Sperling, who considerately takes care of me like my sister would do so with patience and encouragement in both scientific work and daily life. They are not only my scientific and academic guiders in scientific attitude and knowledge, but also my family members in the past three years. I am truly grateful to them for their insightful comments and encouragement, but also for the hard question which incented me to widen my research from various perspectives.

I also thank our collaborator Dr. Sabine Martin (Department of Molecular Biology of Neuronal Signals, Max Planck Institute of Experimental Medicine), Prof. Dr. rer. nat. Kaomei Guan (Institute for Pharmacology and Toxicology, TU Dresden) and Dr. Xingbo Xu (Department of Cardiology and Pneumology, Göttingen University Medical Center) and my teammate Miss Alexandra Sachkova, who gave me access to more research facilities, methods and experience of techniques. By discussing the problems with me they also opened my view, giving me another perspective on my project. Without their support it would not be possible to finish this research. I also would like to thank Julia Bode (Schaller Research Group at the University of Heidelberg and the DKFZ, Heidelberg, Germany) for the generous gift of U87MG cell line, and Christoph Schmitz-Salue for the development of glioblastoma primary cell 
line cultures. Also I thank my other teachers and colleagues in our neurosurgery department. In particular, I am grateful to PD Dr. Ramon Martinez for encouraging me in the first steps of doctorate study. Last but not least, I would like to thank my friend Hannah Gehrmann for helping me with correcting the English writing. 


\section{CURRICULUM VITAE}

My name is Lei Yao, male, born on $5^{\text {th }}$ May 1987 in Nanjing of Jiangsu province in China. I studied in the affiliated High School to Nanjing Normal University from September 2003 to July 2005. Subsequently, I got the permission to study medicine at Nanjing Medical University in September 2005. I got my master degree for medicine in China at Nanjing Medical University in July 2013. During these 8 years of medical education in China, I completed 5 years study in bachelor degree for medicine including 1 year Famulatur at Changzhou No.2 Hospital and 54 weeks PJ in Jiangsu province Hospital, and 3 years surgical master study for medicine in neurosurgery direction including basic clinical and research training in the first affiliated hospital to Nanjing Medical University. During this study, I passed the Chinese medical board examination. In September 2013, I started my medical doctorate study in the Translational Neurooncology Research Group from the Department of Neurosurgery at Georg August University Medical Centre Göttingen. 